\title{
Prion-induced photoreceptor degeneration begins with misfolded prion protein accumulation in cones at two distinct sites: cilia and ribbon synapses
}

\author{
James F. Striebel ${ }^{1}$, Brent Race ${ }^{1}$, Jacqueline M. Leung ${ }^{2}$, Cindi Schwartz ${ }^{2}$ and Bruce Chesebro ${ }^{*}$
}

\begin{abstract}
Accumulation of misfolded host proteins is central to neuropathogenesis of numerous human brain diseases including prion and prion-like diseases. Neurons of retina are also affected by these diseases. Previously, our group and others found that prion-induced retinal damage to photoreceptor cells in mice and humans resembled pathology of human retinitis pigmentosa caused by mutations in retinal proteins. Here, using confocal, epifluorescent and electron microscopy we followed deposition of disease-associated prion protein (PrPSc) and its association with damage to critical retinal structures following intracerebral prion inoculation. The earliest time and place of retinal PrPSc deposition was 67 days post-inoculation (dpi) on the inner segment (IS) of cone photoreceptors. At 104 and $118 \mathrm{dpi}$, PrPSC was associated with the base of cilia and swollen cone inner segments, suggesting ciliopathy as a pathogenic mechanism. By 118 dpi, PrPSc was deposited in both rods and cones which showed rootlet damage in the IS, and photoreceptor cell death was indicated by thinning of the outer nuclear layer. In the outer plexiform layer (OPL) in uninfected mice, normal host PrP (PrPC) was mainly associated with cone bipolar cell processes, but in infected mice, at $118 \mathrm{dpi}$, PrPSc was detected on cone and rod bipolar cell dendrites extending into ribbon synapses. Loss of ribbon synapses in cone pedicles and rod spherules in the OPL was observed to precede destruction of most rods and cones over the next 2-3 weeks. However, bipolar cells and horizontal cells were less damaged, indicating high selectivity among neurons for injury by prions. PrPSc deposition in cone and rod inner segments and on the bipolar cell processes participating in ribbon synapses appear to be critical early events leading to damage and death of photoreceptors after prion infection. These mechanisms may also occur in human retinitis pigmentosa and prion-like diseases, such as AD.
\end{abstract}

Keywords: Prion, Prion-like, Ribbon synapses, Retinitis pigmentosa, Alzheimer, Parkinson, Ciliopathy, Scrapie, Necrosis, Apoptosis

\footnotetext{
*Correspondence: bchesebro@niaid.nih.gov

${ }^{1}$ Laboratory of Persistent Viral Diseases, Rocky Mountain Laboratories,

National Institute of Allergy and Infectious Diseases, National Institutes of Health, 903 South Fourth Street, Hamilton, MT 59840, USA

Full list of author information is available at the end of the article
}

\begin{abstract}
Introduction
Prion diseases are progressive neurodegenerative diseases which affect humans as well as numerous wild and domestic animal species. These diseases are characterized by vacuolar degeneration of the grey matter and gliosis primarily in grey matter of the CNS. In addition, abnormal aggregation of a host prion protein (PrPC) leads to deposition of a protease-resistant PrP isoform (PrPSc) in the nervous system and other organs, which results in damage by unclear mechanisms [25]. Protein aggregation
\end{abstract}

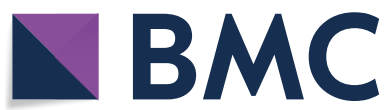

(c) The Author(s) 2021. Open Access This article is licensed under a Creative Commons Attribution 4.0 International License, which permits use, sharing, adaptation, distribution and reproduction in any medium or format, as long as you give appropriate credit to the original author(s) and the source, provide a link to the Creative Commons licence, and indicate if changes were made. The images or other third party material in this article are included in the article's Creative Commons licence, unless indicated otherwise in a credit line to the material. If material is not included in the article's Creative Commons licence and your intended use is not permitted by statutory regulation or exceeds the permitted use, you will need to obtain permission directly from the copyright holder. To view a copy of this licence, visit http://creativecommons.org/licenses/by/4.0/. The Creative Commons Public Domain Dedication waiver (http://creativeco mmons.org/publicdomain/zero/1.0/) applies to the data made available in this article, unless otherwise stated in a credit line to the data. 
in prion disease proceeds by a process referred to as seeded polymerization or PrP conversion, where initial small aggregates of PrPSc catalyze extension of protein aggregation to generate additional PrPSc [9].

A similar seeded polymerization mechanism has been noted in several other more common neurodegenerative diseases including Alzheimer's disease, Parkinson's disease and tauopathies, but in these diseases, the aggregated host proteins are amyloid beta $(\mathrm{A} \beta), \alpha$-synuclein and tau respectively $[4,11,26]$. Because of the similarities in the protein aggregation process in these diseases and prion diseases, they have been referred to as "prion-like" diseases. Some people have suspected that prion diseases and prion-like diseases might be susceptible to similar therapeutic interventions $[22,51]$. Thus, at this time, there is high interest in the mechanisms of pathogenesis of all these diseases.

Prion and "prion-like" diseases are known to cause retinal damage in humans and other species, but each disease affects the retina in unique ways [44]. In Alzheimer's disease patients, $A \beta$ deposition has been associated with degeneration of the retinal ganglion cell layer, photoreceptors and the retinal pigmented epithelium [3, 45]. Ratnayaka et al. have also shown that $\mathrm{A} \beta$ plaques may be a key factor in Age-related Macular Degeneration (AMD). In $\mathrm{AD}$, phosphorylated Tau deposits have also been observed from the outer plexiform layer to the ganglion cell layer $[31,32]$. Likewise, abnormal $\alpha$-synuclein aggregates have been detected in retina of Parkinson's disease patients, and these are implicated in the degeneration of the nerve fiber layer (ganglion cell axons), ganglion cell body layer and inner plexiform layer [57].

In prion disease, results from our lab and others have confirmed deposition of disease-associated PrP (PrPSc) in human, bovine, primate, ovine, cervid, and rodent retina by RT-QuIC, western blot and/or immunohistochemistry $[5,20,21,23,24,29,41,52,54,55,58,60]$. These studies represent examples from both natural disease (human, elk, deer, sheep) and experimental disease (primate, bovine, sheep, rodent). In these studies, damage appeared to affect primarily photoreceptor rods and cones, and damage to other retinal neuronal populations was not clear [50]. In our previous work, mouse photoreceptors were shown to die mainly by the process of apoptosis which coincided with PrPSc deposition $[29,54]$.

Previously, defective iron transport has been proposed as a mechanism of damage in prion-infected eye [47]. Since photoreceptors rely heavily on iron-containing enzymes for the biochemical reactions of the phototransduction pathways, disruption of iron transport by prion infection may also play a role in retinal damage. Such a mechanism might explain the selective damage to photoreceptor cells by prions.
Photoreceptors are also damaged in human retinitis pigmentosa, which is a major cause of human blindness resulting in a retinal pathology similar to prion diseases. In some forms of retinitis pigmentosa, microglia are known to become activated by the misfolding of mutant host proteins such as rhodopsin, and microglia have also been suspected to be important in the pathogenic process $[40,46]$. In prion diseases, microglia activated by the deposition of aggregated prion protein have also been suspected to be a possible mechanism of pathogenesis [18]. However, in our recent studies using PLX5622 to eliminate microglia in vivo, removal of microglia led to a decrease in survival time due to accelerated brain prion pathogenesis in mice [7]. Thus, microglia appeared to be mainly helpful, not harmful, to the host during prion disease. Furthermore, in our studies of retinal prion disease in mice, elimination of microglia gave similar results, showing accelerated retinal degeneration when microglia were reduced or absent [54]. Müller glial cells are also activated during prion disease but are likely a response to damage rather than the cause of pathogenesis [28, $29,58]$. Thus, in vivo damage induced by prion infection might be due to direct effects of aggregated prion protein on photoreceptor cells rather than indirect effects of activated microglia or astroglia.

In the present paper, we studied direct early events of prion protein deposition in mouse retina following intracerebral prion injection. For these studies, we used confocal and epifluorescence microscopy with detection of multiple targets on the same section to localize $\operatorname{PrP}$ in its normal and disease-associated forms, while also observing multiple subcellular components of retinal rods, cones, bipolar cells and horizontal cells. Ultrastructural studies were also done to confirm some of the observations. The results showed early deposition of PrPSc in two distinct, subcellular areas of retina as well as interesting novel events of photoreceptor damage in both these areas which preceded the death of both rods and cones while sparing other nearby cell types.

\section{Materials and methods}

\section{Ethics statement}

All mice were housed at the Rocky Mountain Laboratories (RML) in an AAALAC-accredited facility in compliance with guidelines provided by the Guide for the Care and Use of Laboratory Animals (Institute for Laboratory Animal Research Council). Experimentation followed RML Animal Care and Use Committee approved protocol 2016-042.

\section{Mice}

Retinas used in these experiments were obtained from two strains of mice, C57BL/10SnJ and 
C57BL/6 J-TgGFP/RFP. 79A scrapie-induced retinal degeneration is very similar in these strains and was characterized in our previous publication [54]. An inhouse breeding colony supplied C57BL/10SnJ mice, and C57BL/6 J-TgGFP/RFP were also bred in-house as previously described [54]. The GFP and RFP fluorescence was not important to the questions addressed here. All mice were group housed in transparent cages in a $12 \mathrm{~h}$ light (250-300lux) /12 h dark cycle and food and water were available ad libitium.

\section{Scrapie inoculation model}

Scrapie inoculations were carried out as previously described [54]. Briefly, mice (4-6 weeks old) were injected intracerebrally (i.c.) in the left hemisphere with $30 \mu \mathrm{l}$ of a $1 \%(\mathrm{wt} / \mathrm{vol})$ dilution of brain homogenate pools from C57BL mice terminally ill from 79A scrapie. Brain homogenates contained $1.0 \times 10^{5}$ ID50 / 30 ul after they were diluted for inoculation in phosphatebuffered balanced saline (PBBS) pH 7.2, supplemented with $2 \%$ fetal bovine serum (Hyclone, Logan, UT).

The course of disease, details on the clinical symptoms and retinal degeneration were previously well documented in the mouse strains used in this study in our previous publication [54]. Briefly, in the 79A mouse-adapted scrapie model, mice begin showing clinical signs consistent with scrapie between 105 and 120dpi and reach clinical endpoint disease at approximately 160dpi. Thinning of the retina begins around 118dpi and likely causes blindness by the disease endpoint, though this diagnosis is difficult to determine without conducting further tests. The 79A scrapie strain was previously compared to seven other strains of mouse-adapted scrapie and shown to be the most retinal-tropic [15]. At pre-clinical and clinical time-points, mice were euthanized by isoflurane anesthesia overdose followed by perfusion with $10 \mathrm{ml}$ of saline.

\section{Immunohistochemistry and Immunofluorescence}

For immunohistochemistry and immunofluorescence, eyes were removed, placed in $10 \%$ neutral buffered formalin for 3 to 5 days and then processed by dehydration and embedded in paraffin as a single block. Next, $5 \mu \mathrm{m}$ sections were cut using a standard Leica microtome, placed on positively charged glass slides, and air-dried overnight at room temperature. The following day slides were heated in an oven at $60{ }^{\circ} \mathrm{C}$ for $20 \mathrm{~min}$. A Ventana automated Discovery XT stainer was used for deparaffinization, antigen retrieval and immunohistochemical staining.

For immunohistochemical staining of $\operatorname{PrP}$ antigens were exposed by incubation in CC1 buffer (Ventana) containing Tris-Borate-EDTA, $\mathrm{pH} 8.0$ for $100 \mathrm{~min}$ at
$95{ }^{\circ} \mathrm{C}$. Staining for $\operatorname{PrP}$ was done using human antiPrP monoclonal antibody D13 [33] which was obtained from tissue culture supernatants made in our laboratory from $\mathrm{CHO}$ cells expressing the D13 antibody construct, which were kindly provided by Dr. R. Anthony Williamson, The Scripps Research Institute, La Jolla, CA. D13 culture fluid was used at a dilution of 1:100 (diluted in PBS with $1 \%$ normal goat serum and $0.1 \%$ Triton X-100) for $2 \mathrm{~h}$ at $37{ }^{\circ} \mathrm{C}$. The secondary antibody was biotinylated goat anti-human IgG at 1:500 dilution (Jackson ImmunoResearch, West Grove, PA.), and avidin-horseradish peroxidase was used with $D A B$ as chromogen (DAB Map kit; Ventana Medical Systems, Tucson, AZ.).

For immunofluorescent staining, antigen retrieval for all targets was performed using a Biocare Medical DC2002 Decloaking chamber with sodium citrate buffer at $\mathrm{pH} 6.0(0.01 \mathrm{M})$ for $20 \mathrm{~min}$ at $120^{\circ} \mathrm{C} / 20 \mathrm{PSI}$ and cooled to $50{ }^{\circ} \mathrm{C}$. For each of the following steps, 250 $300 \mu \mathrm{l}$ of solution was applied to each slide and covered with a temporary plastic coverslip and incubated for a set amount of time. Tissues were blocked first with a normal donkey serum blocking solution (2\% donkey serum, $1 \%$ BSA, $0.1 \%$ Triton X-100, 0.05\% Tween 20 in 0.01 M PBS) for $1 \mathrm{~h}$ at room temperature and then in $0.1 \mathrm{M}$ Glycine in $0.01 \mathrm{M}$ PBS for $30 \mathrm{~min}$ at room temperature. Primary antibodies (Table 1.) were diluted in donkey serum blocking solution and applied for $1 \mathrm{~h}$ at room temperature. Alexafluor (ThermoFisher) secondary antibodies were diluted to 1:250 in donkey serum solution and applied for $1 \mathrm{~h}$. In dual or triple stainings, primary antibodies were applied simultaneously, as were secondary antibodies. After each antibody incubation, slides were washed 3 times in $1 \mathrm{X}$ PBS for $10 \mathrm{~min}$. Coverslips were mounted with ProLong Gold with DAPI (Life Technologies) and examined and photographed using an Olympus BX51 microscope/Olympus CellSens software or using a confocal microscope as described below.

\section{Numbers of mice studied}

The numbers of animals analyzed at each timepoint are presented in Table 2. Uninfected mice used as controls were of similar age to experimental animals, evidence of age-related retinal changes was not observed in the age range of control animals used.

\section{Nomenclature and detection of PrP, PrPC and PrPSc}

Monoclonal antibody D13 was used in immunostaining of tissue sections to detect PrP. In tissues of uninfected mice, PrP detected was assumed to be the normal PrP isoform, PrPC. In infected tissues, PrP detected in locations different from those seen uninfected mice was assumed to be disease-associated PrPSc, and PrP 
Table 1 Primary Antibodies used in immunofluorescent staining

\begin{tabular}{|c|c|c|c|c|}
\hline Antibody & Specificity (antigen/cell type or structure) & Dilution & Host species & Source \\
\hline D13 & Prion protein & $1: 100$ & Human & Ref, Matsunaga \\
\hline Cone Arrestin & Arrestin 3/Cone photoreceptors & $1: 100$ & Rabbit & Millipore, AB15282 \\
\hline Cone Opsin & Red, Green opsins/Cone photoreceptors & $1: 100$ & Rabbit & Chemicon, AB5404 \\
\hline Rhodopsin & Rhodopsin/Rod photoreceptors & $1: 100$ & Rabbit & Millipore, MABN15 \\
\hline GNAT1 & $\begin{array}{l}\text { G protein subunit alpha transducin } 1 \\
\text { /Rod photoreceptors }\end{array}$ & $1: 100$ & Rabbit & Abcam, ab74059 \\
\hline GNAT2 & G protein subunit alpha transducin 2 /Cone photoreceptors & $1: 100$ & Rabbit & Thermofisher, PA5-22,340 \\
\hline GLUT1 & Glucose transporter 1/Cell membranes of many cell types & $1: 100$ & Rabbit & Abcam, ab115730 \\
\hline CtBP2 & C-terminal binding protein 2/ribeye protein of ribbon synapses & $1: 100$ & Rabbit, mouse & $\begin{array}{l}\text { Invitrogen, PA-79086 } \\
\text { Santa Cruz, sc-17759 }\end{array}$ \\
\hline PKCa & Protein kinase C/Rod bipolar cells & $1: 100$ & Rabbit, mouse & Invitrogen PA5-17,551, MA1-157 \\
\hline Calbindin & Calbindin/Horizontal cells & $1: 100$ & Rabbit & Abcam, ab108404 \\
\hline Rootletin & Rootletin/photoreceptor rootlets & $1: 50$ & Mouse & Millipore, ABN1714 \\
\hline Centrin3 & Centrin3/cilia and basal bodies in photoreceptor inner segments & $1: 100$ & Rabbit & Thermofisher, PA5-35,865 \\
\hline Secretagogin (SCGN) & Cone bipolar cells ${ }^{a}$ & $1: 100$ & Rabbit & Thermofisher, PA5-30,393 \\
\hline
\end{tabular}

a SCGN marks 8 of the 12 subtypes of mouse cone bipolar cells [13, 42]

detected in similar locations to those found in uninfected mice was assumed to be either or both isoforms.

\section{Quantification of bipolar and horizontal cells}

To quantify rod bipolar cells throughout the timecourse of disease, two sections of retina from a mouse at each timepoint were stained with DAPI, anti-PKC $\alpha$ primary antibody and secondary antibody Alexa Fluor 488 as described above. The PKC $\alpha$-positive rod bipolar cell bodies were counted in four 20X fields per timepoint and averaged. Horizontal cell numbers were determined by staining retinal sections with DAPI, anti-calbindin primary antibody and Alexa Fluor 488 secondary antibody as described above. Calbindin-positive cell bodies were counted along two entire retinal sections from one mouse per timepoint. Cone bipolar cells were counted by staining retinal sections with anti-secretagogin antibody, which labels 8 of the 12 types of cone bipolar cells [13, $42]$ and counting cell bodies on two retinal sections from at least one mouse per timepoint (see figure legend for $\mathrm{n}$ values). One-way ANOVA statistical analysis was performed using GraphPad Prism software.

\section{Confocal microscopy}

All samples were handled and chemically decontaminated according to established scrapie protocols in consultation with RML Biosafety. Samples were imaged using a Zeiss laser scanning confocal (LSM 880) microscope driven by ZEN v.2.3 software (Carl Zeiss Microscopy). A Plan Apochromat 63X/NA1.4 oil immersion lens was used, with immersion oil at a refractive index of
1.518. Image acquisition settings including laser power and gain were optimized for minimal background and cross-talk, and kept constant within an experiment for all timepoints and samples to enable direct comparisons. Stacks were collected with a lateral resolution of $43 \mathrm{~nm}$ and $\mathrm{z}$-spacing of $130 \mathrm{~nm}$ except for: quantification of anti-D13 and anti-CtBP2 signals, where stacks were collected with a lateral resolution of $71 \mathrm{~nm}$ and $\mathrm{z}$-spacing of $367 \mathrm{~nm}$, with five representative fields of view acquired for each timepoint, and anti-Cone Opsin, anti-GNAT1, anti-Cone Arrestin, anti-Centrin3 which were collected with a lateral resolution/z-spacing of $18 \mathrm{~nm} / 250 \mathrm{~nm}$, $132 \mathrm{~nm} / 250 \mathrm{~nm}, 65 \mathrm{~nm} / 500 \mathrm{~nm}$ and $70 \mathrm{~nm} / 500 \mathrm{~nm}$ respectively.

\section{Image processing and analysis}

Image stacks were exported from ZEN software and deconvolved with Huygens Professional v. 20.04 (Scientific Volume Imaging, The Netherlands) using the CMLE algorithm, with $\mathrm{SNR}=20$ and a maximum of 40 iterations. The deconvolved datasets were imported to Imaris x86_64 v.9.5.1 (Bitplane AG, Zürich, Switzerland) for segmentation, surface rendering, visualization, and quantification. The average number of CtBP2 ribbons based on anti-CtBP2 signal and amount of total integrated antiD13 signal was calculated per micron length of retina. Data were imported into Microsoft Excel for compilation, and statistical analysis was performed using GraphPad Prism v 8.3.0 (La Jolla, CA). 


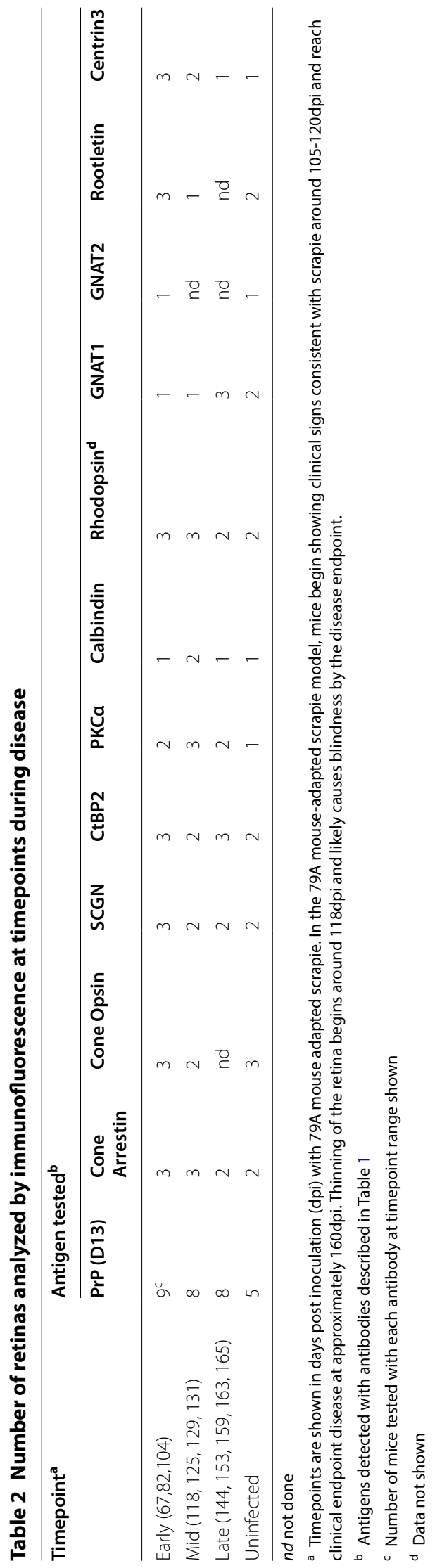




\section{Electron microscopy sample preparation}

C57BL/10SnJ mice were perfused with $2 \%$ paraformaldehyde $+2 \%$ glutaraldehyde in $0.1 \mathrm{M}$ Sorensen's phosphate buffer (Electron Microscopy Sciences, Pennsylvania). Eyes were enucleated and placed in fresh fixative for at least $30 \mathrm{~min}$ before further for processing. The anterior portions of eyes were dissected and discarded. The remaining posterior eye cups were rinsed in phosphate buffer, followed by embedment in $2.5 \%$ low-melt agar (Precisionary, Massachusetts) made in PBS. $200 \mu \mathrm{m}$ sections were cut with a VT1000S vibrating blade microtome (Leica Biosystems, Illinois). Sections were processed for transmission electron microscopy as follows: postfixation with $0.05 \%$ osmium tetroxide $+0.08 \%$ potassium ferrocyanide in $0.1 \mathrm{M}$ phosphate buffer for $1 \mathrm{~h}$, rinsed with buffer, then dehydrated in a graded ethanol series to $100 \%$, infiltrated with LRWhite (Electron Microscopy Sciences, Pennsylvania) and polymerized overnight in homemade flat-embedding molds covered with aclar sheets at $50{ }^{\circ} \mathrm{C}$ in a vacuum oven.

For electron microscopy studies the following numbers of retinas from C57BL/10SnJ mice were taken at the given timepoints; uninfected $(\mathrm{n}=22), 84 \mathrm{dpi}(\mathrm{n}=2)$, 89 dpi $(n=4), 98$ dpi $(n=2), 104$ dpi $(n=3), 112$ dpi $(\mathrm{n}=2), 122$ dpi $(\mathrm{n}=4), 126 \mathrm{dpi}(\mathrm{n}=2), 132 \mathrm{dpi}(\mathrm{n}=3)$, 137 dpi $(n=3), 140$ dpi $(n=1), 151$ dpi $(n=3), 154$ dpi $(n=1), 165$ dpi $(n=3)$. These retinas were embedded in various resins (Durcupan, Araldite, HM20, and LRWhite) and examined. The LRWhite embedded retinas were selected for the imaging and comparisons shown in this paper. The numbers at each timepoint were; uninfected $(\mathrm{n}=4)$, 104dpi $(\mathrm{n}=1), 126 \mathrm{dpi}(\mathrm{n}=1), 132 \mathrm{dpi}(\mathrm{n}=1)$, $137 \mathrm{dpi}(\mathrm{n}=2), 151 \mathrm{dpi}(\mathrm{n}=2)$.

\section{Transmission electron microscopy}

Flat-embedded vibratome sections were excised and super-glued onto resin stubs such that ultramicrotomy sections would be in the desired orientation. $70 \mathrm{~nm} \mathrm{sec-}$ tions were cut with a Ultracut UCT (Leica Biosystems, Illinois) ultramicrotome and picked up on Formvar coated 100 hex mesh copper grids (Electron Microscopy Sciences, Pennsylvania). Micrographs were acquired on a HT7800 (Hitachi, Oregon) operating at $80 \mathrm{kV}$ with an XR-81B CMOS digital camera (AMT Imaging Systems, Massachusetts).

\section{Results}

\section{Detection of PrPSc in retina after intracerebral scrapie} injection.

In the current experiments, prion infection of retina was achieved by intracerebral inoculation of mice with $1.0 \times 10^{5}$ ID50 units of scrapie strain $79 \mathrm{~A}$. With this method, prions are known to spread to the retina via the optic tract and optic nerve $[6,16]$. Progression of retinal infection was followed by immunohistochemistry (IHC) or immunofluorescence (IF) with anti-PrP monoclonal antibody D13 to detect PrP. In uninfected PrPKO mice, no PrP signal was detected by IHC or IF (Fig. 1a, b). However, in uninfected mice expressing PrP, staining of PrP was clearly detectable by IHC and IF in an irregular clumpy distribution in the outer plexiform layer

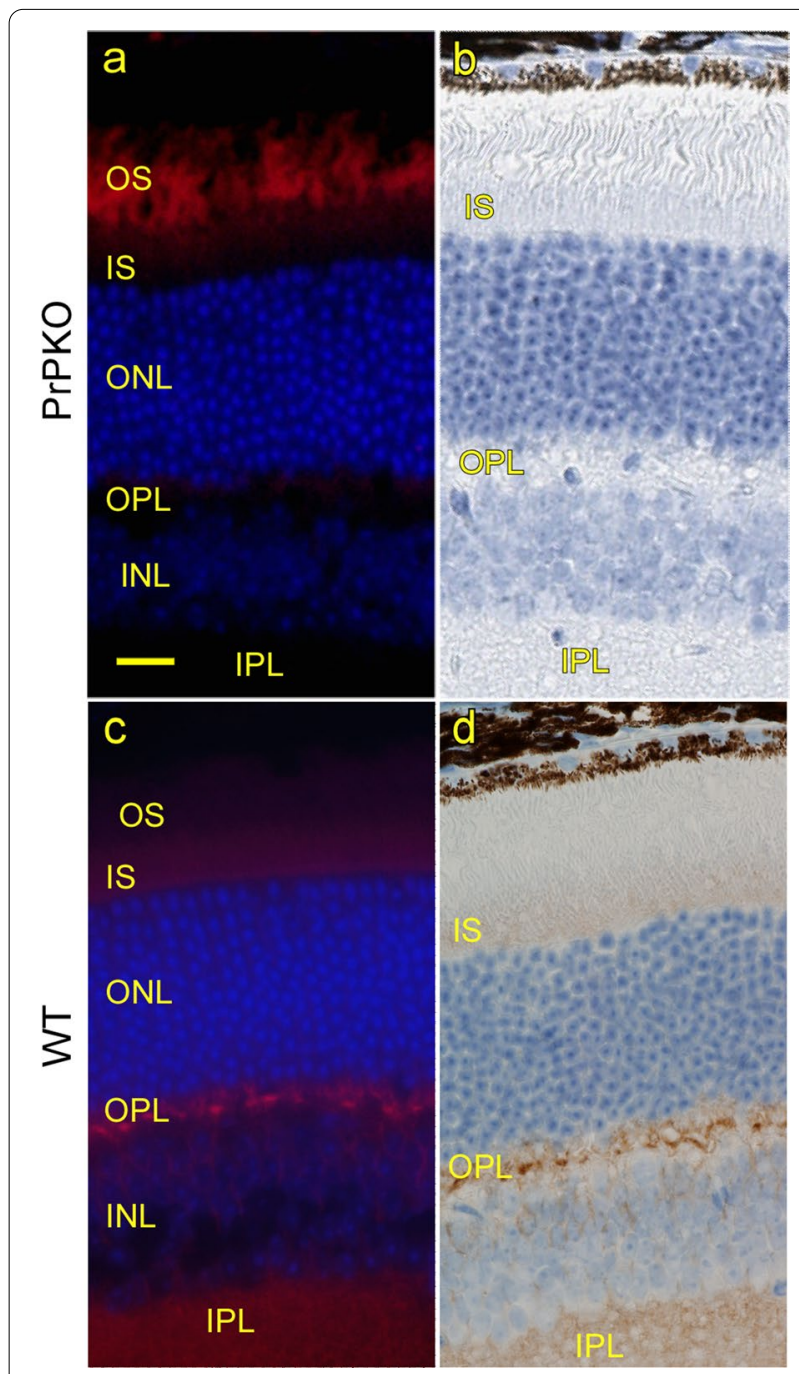

Fig. 1 PrPC expression in uninfected PrP knockout (PrPKO) and wild-type (WT) retina using D13 antibody. a, b In PrPKO retina, normal host PrP (PrPC) was not detected by immunofluorescent stain (red) or immunohistochemical stain (brown). However, photoreceptors in OS of PrPKO retina showed red autofluorescence, a common but variable artifact of immunofluorescence studies of retina. $\mathbf{c}, \mathbf{d} \ln$ WT retina, PrPC was observed by both staining techniques in the OPL and IPL, and weaker levels were detected in the INL and IS. Scale bar in $\mathbf{a}=20 \mu \mathrm{m}$. OS outer segment, IS inner segment, ONL outer nuclear layer, OPL outer plexiform layer, INL inner nuclear layer, IPL inner plexiform layer 
Fig. 2 Timecourse of PrP staining with D13 antibody in retina at various times after infection with strain 79A scrapie prions. a Uninfected mouse showing PrPC (magenta) mainly in OPL. b, c At 82 and 104 days post infection (dpi) the misfolded, disease-associated form of PrP (PrPSC) (magenta) can now be seen in the IS and OPL at progressively wider areas. $\mathbf{d}$ At $118 \mathrm{dpi}$, PrPSc is widespread in the IS and deposits are not restricted to discrete individual cells. Some small deposits are visible in the ONL and ONL is beginning to thin as photoreceptors die. e At $131 \mathrm{dpi}$, PrPSC is deposited in the IS and OPL, and ONL is much thinner. $\mathbf{f}$ PrPSC staining appears less at $162 \mathrm{dpi}$ in IS and $\mathrm{OPL}$, and ONL is dramatically thinner. Punctate PrPSC is present in IPL (arrowhead). Scale bar in $\mathbf{a}=20 \mu \mathrm{m}$

(OPL) and in a more diffuse pattern in the inner plexiform layer (IPL) (Fig. 1c, d). This was similar to what has been described previously by others $[10,17,19]$. In addition, a smooth faint signal was observed in the inner segment (IS) of the photoreceptor layer (Fig. 1c, d) [54]. All of these sites were likely to represent normal cellular PrP $(\mathrm{PrPC})$ as they were not seen in PrPKO mice (Fig. 1a, b).

At 82 days post-infection (dpi), bright punctate PrP staining in patchy aggregates of varying sizes were seen in an irregular scattered distribution along the IS and OPL layers (Fig. 2b). This staining was likely to be disease-associated PrPSc, as it was not seen in uninfected mice (Figs. 1c, d, 2a). At 104 and 118 dpi, the PrPSc staining in the IS and OPL was more extensive, and at 118 dpi, PrPSc staining was often seen on the entire circumference of the IS and OPL (Fig. 2c, d). At $118 \mathrm{dpi}$, there was also a decrease in the width of the outer nuclear layer (ONL) indicating a loss of photoreceptor cell nuclei. At $131 \mathrm{dpi}$, the ONL was further reduced in size, and the PrPSc staining in the IS and OPL was decreased in intensity (Fig. 2e). At $162 \mathrm{dpi}$, all retinal layers were thinned (Fig. 2f), and the ONL was now only 2-3 cells thick in most areas. Faint PrPSc staining was further decreased in the IS and OPL regions but was now slightly more detectable in the inner plexiform layer (IPL). Interestingly, this type of neurodegeneration was not seen in uninfected PrPKO mice, which suggested that loss of PrP does not itself cause photoreceptor degeneration (unpublished results from our group).

The time course of PrPSc deposition and retinal degeneration seen in these experiments using indirect IF was similar to our previous data using detection of PrP by IHC [54]. However, the details of the PrPSc aggregate morphology was seen more clearly by IF. Since photoreceptor rods and cones are the main cells normally present in the IS region and these cells also have processes
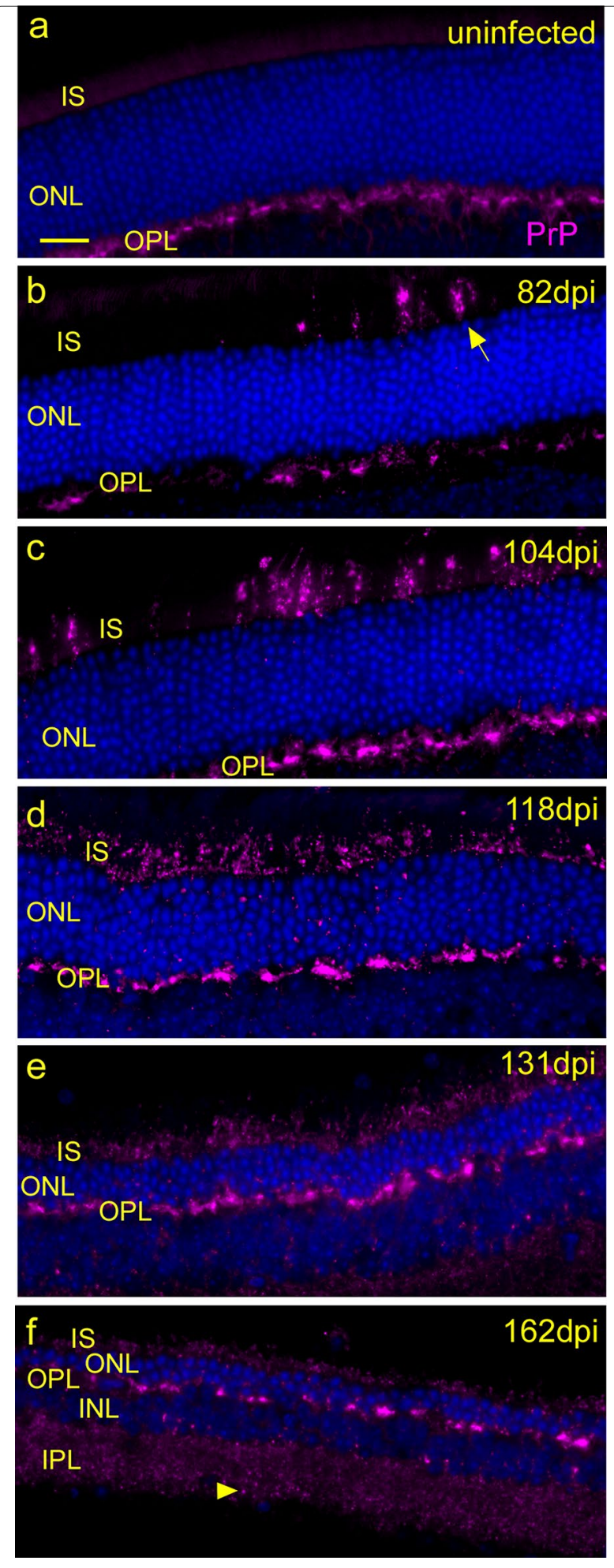
Fig. 3 PrPSc accumulates first in cone photoreceptor inner segments. a At 67 dpi, rare small punctate PrPSc deposits (arrow) are present on cone photoreceptors marked with Cone Arrestin (green). Magenta in outer segment is autofluorescence of rhodopsin. $\mathbf{b}$ Cone opsin (white) marks cone outer segments with PrPSc (magenta) deposits associated mainly with cone inner segments (yellow arrow) at $104 \mathrm{dpi}$. The transition from faint to intense cone opsin staining marks the boundary between cone IS and cone OS (blue arrow). c Another cone-specific outer segment protein GNAT2 (green) shows obvious connection with PrPSc (magenta) staining cone inner segments at 104 dpi (arrows). d At 104 dpi, rod-specific marker, GNAT1 (green) stains rod inner and outer segments, but spares cones (arrowheads). PrPSc (magenta) accumulations are present in the dark GNAT1-free areas (arrows). e A separate experiment done with $22 \mathrm{~L}$ scrapie strain shows same association of PrPSc with cone inner segments at 123 dpi, suggesting cone specificity is not strain-specific. Scale bar $=5 \mu \mathrm{m} . \mathbf{a}, \mathbf{b}, \mathbf{d}$ are confocal z-stacks, $\mathbf{c}$, e are widefield images

extending into the OPL, early PrPSc deposition was likely to be associated with one or both of these photoreceptor cell types. To study the cell types associated with PrPSc in this model, we used the IF method with dual staining for PrP and antibodies reactive with cone- or rod-specific proteins (Tables 1, 2).

\section{Deposition of PrPSc occurs first in cone photoreceptors}

At $67 \mathrm{dpi}$, PrPSc was detected in a few individual cells in the IS region, and this PrPSc was associated with detection of cone arrestin in the same individual cells (Fig. 3a). Similarly, at $104 \mathrm{dpi}$, PrPSc staining was associated with detection of cone opsin (Fig. 3b) and GNAT2 (transducin alpha-2), another cone-specific marker (Fig. 3c). In both of these examples, the PrPSc staining was in the inner portion of the IS, whereas both the cone opsin and GNAT2 proteins were mostly in the outer segment (OS), i.e. distal to the PrPSc but appearing to be in the same individual cells as the cone-specific marker proteins. In contrast, GNAT1 (transducin alpha-1), a rod-specific protein, did not co-associate with PrPSc at 104 dpi which was located in the dark spaces not stained by GNAT1, i.e. cones (Fig. 3d). Because scrapie strains have been shown to show cell-specific infectivity [8], we tested the 22L strain, which also targeted cone photoreceptors before rods (Fig. 3e). These observations indicated that PrPSc deposition appeared first in cone photoreceptor inner segments. Additional studies showed that rods were also infected starting around $118 \mathrm{dpi}$ (see below).

Retinas were next studied by confocal microscopy to look for cone damage by dual staining with anti-PrP and
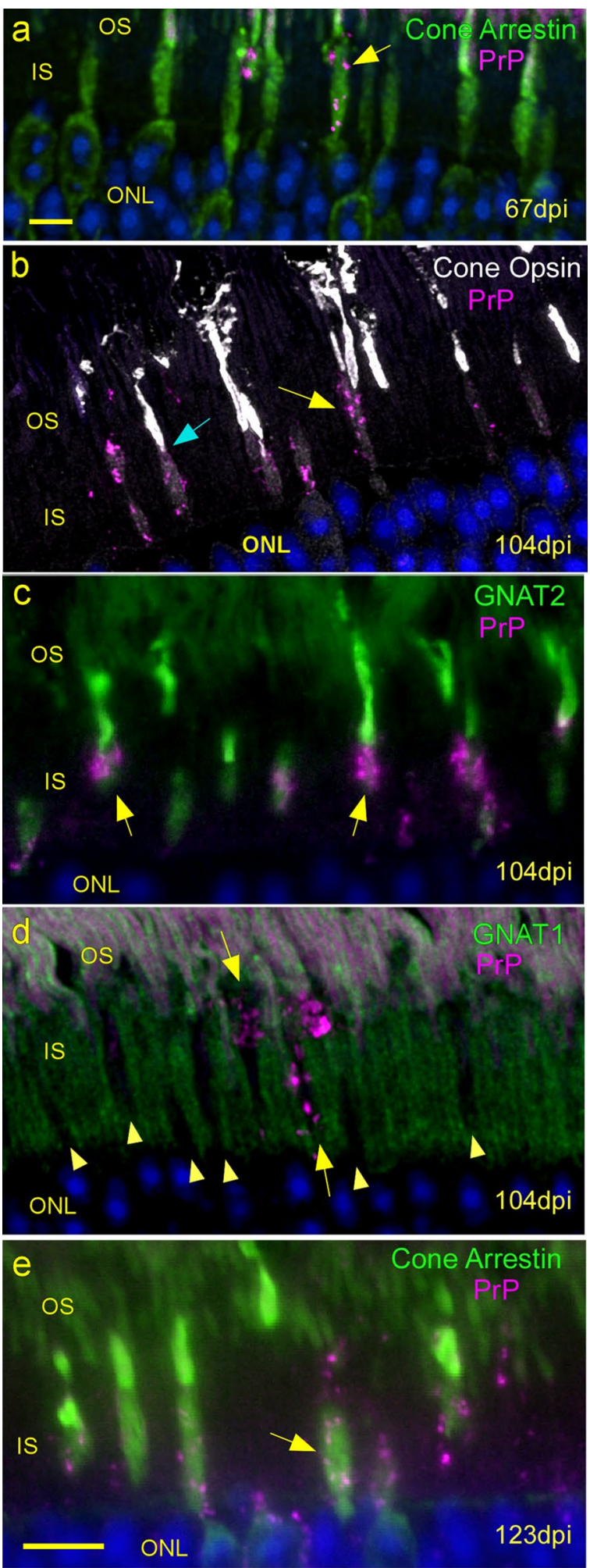

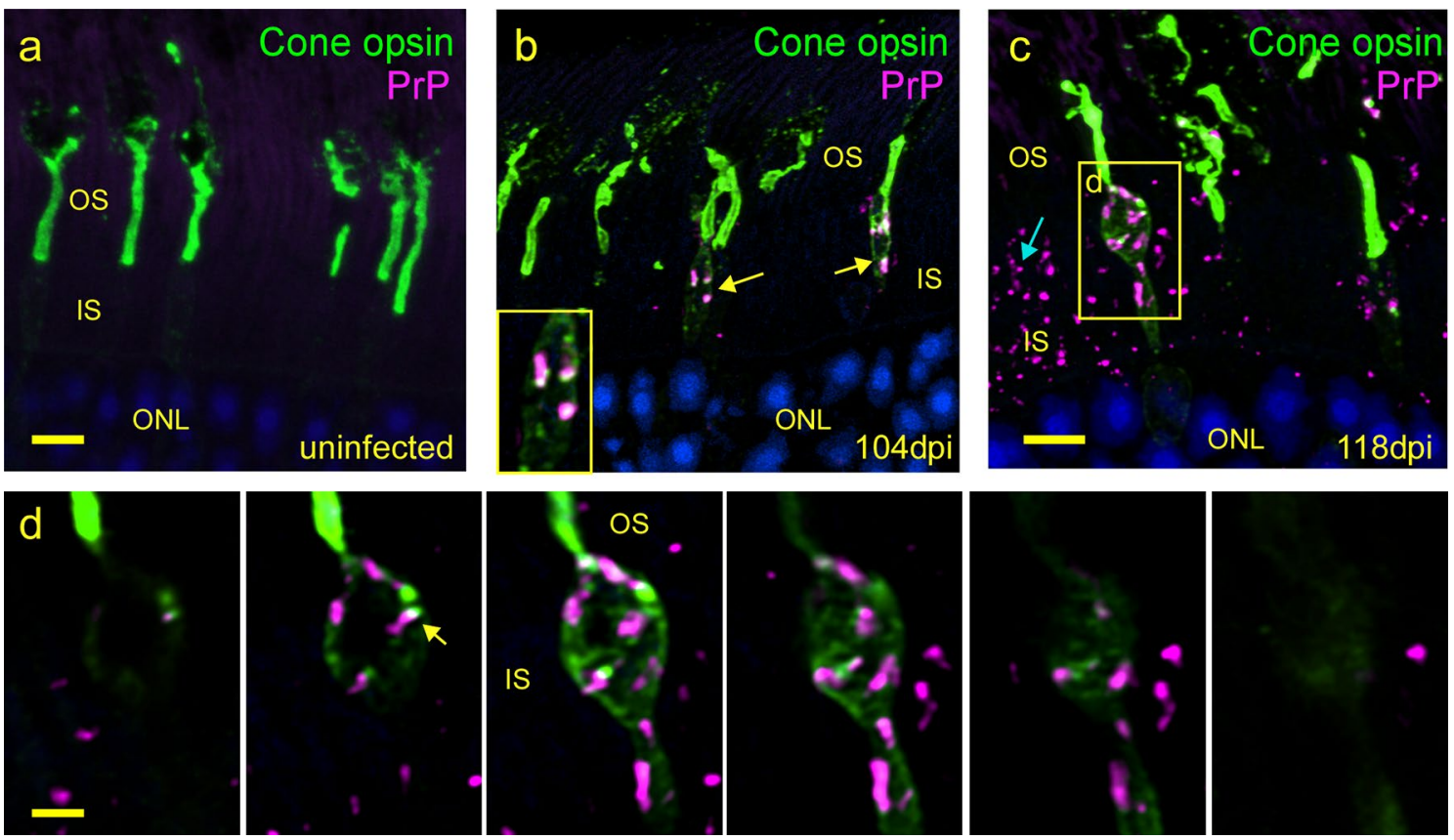

Fig. 4 Early PrPSC accumulation associated with cone photoreceptor damage. a Uninfected retina shows normal cone morphology and distribution of cone opsin (green) in outer segment. b At 104 dpi early PrPSc deposits are associated with cone inner segments (arrow) and some PrPSc appears to localize with cone opsin (white areas in $\times 2$ magnified inset). c At 118 dpi, a swollen, dystrophic cone with PrPSc is seen (yellow box) and some PrPSc is also present in rods (blue arrow). $\mathbf{d}$ Serial confocal sections spaced $0.5 \mu \mathrm{m}$ apart, magnify the swollen cone inner segment from $\mathbf{c}$ and suggests the PrPSc is inside the inner segment along with mistrafficked cone opsin. Scale bar in $\mathbf{a}$ and $\mathbf{c}=5 \mu \mathrm{m}$. Scale bar in $\mathbf{d}$ series $=2 \mu \mathrm{m}$. $\mathbf{a}-\mathbf{c}$ are confocal z-stacks

anti-cone opsin. At 104 dpi, swelling in the inner segment portions of some PrPSc-positive cones was observed (Fig. 4b). This swelling was never seen in uninfected retinas (Fig. 4a), and therefore appeared to be a sign of damage due to prion infection. This swelling was typical of necrotic cell death as described in cone degeneration in a rd10 mouse model [37]. At 118 dpi abundant PrPSc was seen in cones and in the inner segment cells lacking cone opsin (Fig. 4c), indicating that prion infection had spread to rods by this time. Six serial optical sections through the cone outlined in Fig. 4c revealed that PrPSc (red) and cone opsin (green) were mostly separated inside this cone
(Fig. 4d). However, the detection of cone opsin outlining the outer edge of the cytoplasm was not seen in cells lacking PrPSc, suggesting that this unusual distribution of cone opsin may be a manifestation of prion-induced damage in this cone.

\section{Detection of PrPSc-associated damage in the inner segment}

To understand how PrPSc deposition might be causing damage to cone (and rod) photoreceptors we looked for association of PrPSc with additional key inner segment structures. First, the relationship between PrPSc

\footnotetext{
(See figure on next page.)

Fig. 5 Early PrPSc accumulation and damage in the inner segment. a Cartoon of cone photoreceptor shows key structures related to PrPSc deposition. cc connecting cilium, bb basal body, $r$ rootlet, $m$ mitochondria, $c p$ cone pedicle, $r$ ribbon synapse. b Anti-centrin3 antibody (green) marks the connecting cilium and basal body (small green dots) of all photoreceptors. PrPSc (magenta) accumulation at entrance to connecting cilium (arrow), magnified in inset. c Serial $0.5 \mu \mathrm{m}$ confocal sections (c1-6) showing relative localization of PrPSc, cilium and basal body. $\mathbf{d}$ Cone arrestin (green) staining of uninfected cone photoreceptor. Arrow indicates likely position of connecting cilium. e 118 dpi shows retina stained for cone arrestin (green) and PrP (magenta). Asterisks mark cones missing outer segments, yellow arrows point to position of connecting cilia and associated PrPSc (magenta) deposit, and arrowheads show dystrophic outer segments. f, $\mathbf{g}$ Confocal analysis showing xy and yz planes of swollen cones from e confirm the presence of PrPSc at the location of the connecting cilium (arrow) between the IS and OS. $\mathbf{h}$ In an uninfected retina, anti-rootletin (green) antibody stains the rootlets of photoreceptors. i, j At later days post infection, PrPSc (magenta) is increased, rootlets are fewer in number and misshapen. Scale bars: $\mathbf{b}, \mathbf{e}=5 \mu \mathrm{m} ; \mathbf{c}=1 \mu \mathrm{m} ; \mathbf{d}=2 \mu \mathrm{m} ; \mathbf{f}, \mathbf{g}=2 \mu \mathrm{m} ; \mathbf{h}=10 \mu \mathrm{m}$. b, $\mathbf{d}$, e Maximum intensity projections (MIP) of confocal z-stacks $\mathbf{h}, \mathbf{i}, \mathbf{j}$ are widefield images
} 

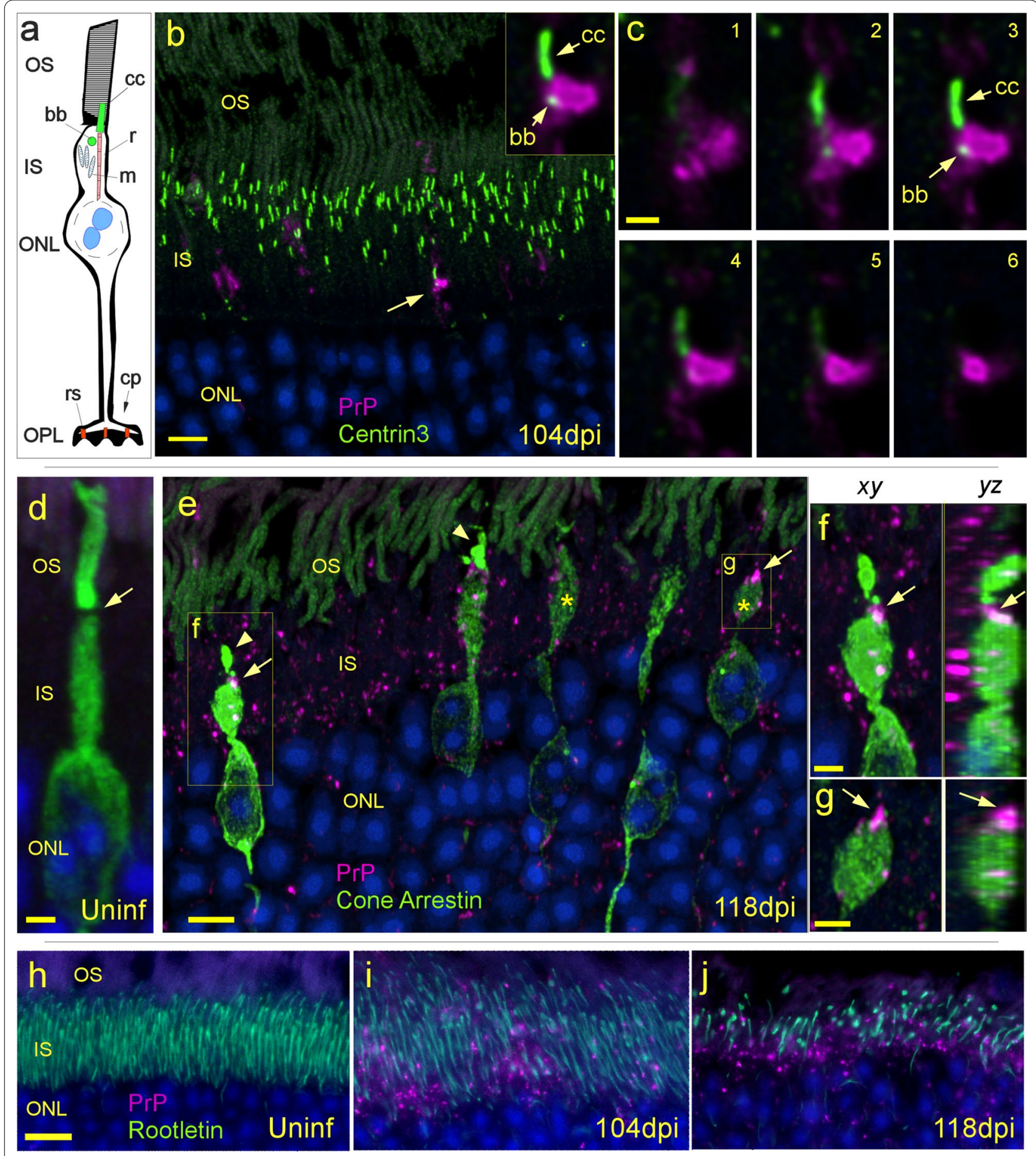

deposition and the cilium connecting the inner and the outer segments of the photoreceptor cells (Fig. 5a) was examined by dual staining for $\operatorname{PrP}$ and Centrin3, a protein located within the cilia of rods and cones. Early in disease, at $104 \mathrm{dpi}$, deposition of PrPSc could often be detected near the entry point of the connecting cilium (Fig. 5b). In some cases, PrPSc was directly adjacent to the cilium, as confocal analysis showed that PrPSc, basal body and cilium could be found within the same section (Fig. 5c). The deposition of PrPSc at this site may have 

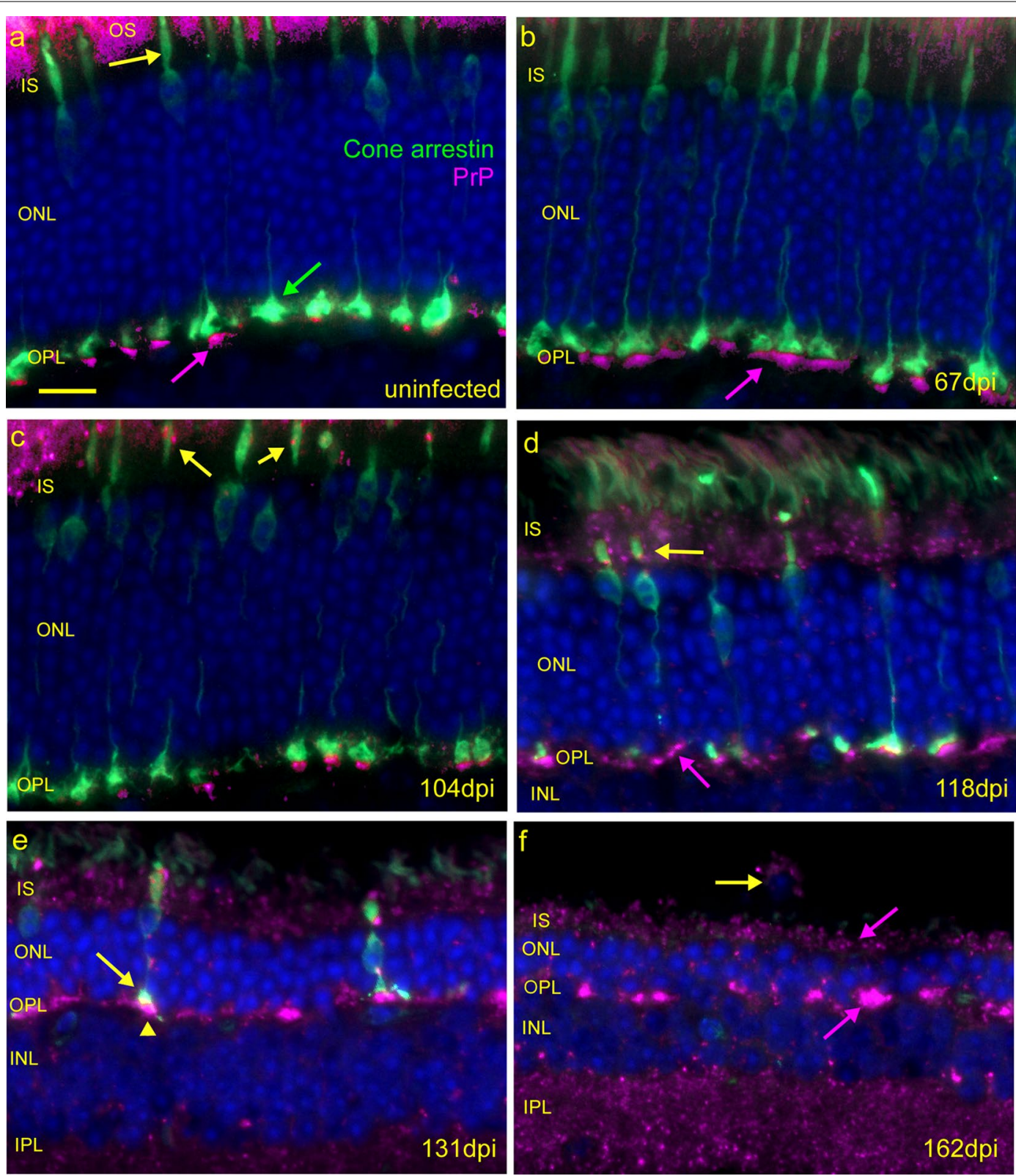

Fig. 6 Timecourse of damage to cone photoreceptors. a Anti-Cone arrestin (green) stains cone photoreceptor, inner segments (yellow arrow) and pedicles (green arrow) in an uninfected mouse. Anti-PrP antibody D13, stains PrPC (magenta) at the base of cone pedicles in the OPL (purple arrow). Autofluorescence is also present in the OS. b At $67 \mathrm{dpi}$ cone arrestin and PrP are distributed similarly to uninfected retina (magenta arrow). c Small deposits of PrPSC are present in the IS at $104 \mathrm{dpi}$ and are associated with cones (arrows). $\mathbf{d}$ At $118 \mathrm{dpi}$, the number of cones is reduced (green), most cone pedicles have disappeared from the OPL and the remaining cones are dystrophic (yellow arrow), missing their outer segments. PrPSC is widespread in the IS and ONL. e Few cones (green) remain at $131 \mathrm{dpi}$, pedicles (arrow) are much smaller in size and associated with dense clumps of PrPSC (arrowhead). f Cones are not detectable at $162 \mathrm{dpi}$, and ONL is 2-3 nuclei thick, suggesting rod photoreceptors have mostly died. A macrophage or microglial cell (yellow arrow) containing PrPSc is present in the remnants of the OS. Scale bar in $\mathbf{a}=20 \mu \mathrm{m}$, applicable to all images

affected the cilium's ability to transport phototransduction proteins between the IS and OS. Ciliary dysfunction is known to cause photoreceptor death in other forms of retinal degeneration [43].
To test this idea, we stained for cone arrestin, a conespecific phototransduction protein, known to be trafficked between the IS and OS [2, 49]. In uninfected retinas, cone arrestin was present in the OS, IS, ONL (Fig. 5d) and pedicles (Fig. 6). The cone outer segments 
of a 118 dpi retina appeared shrunken and malformed compared to an uninfected cone and in some cases, outer segments were absent (Fig. $5 \mathrm{~d}-\mathrm{g}$ ). Inner segments of cones in the 118 dpi retina were often swollen, and PrPSc deposits could be found at the constriction point between the IS and OS, i.e. the location of the connecting cilium (Fig. $5 \mathrm{~d}-\mathrm{g}$ ). Together these data suggest that deposition of PrPSc in the inner segment may have affected the ciliary transport of cone arrestin and/or other proteins. We also investigated the association of PrPSc deposits with another prominent inner segment structure, the rootlet, which functions to stabilize the connecting cilium [59] (Fig. 5a). For this, we used an antirootletin antibody together with D13 anti-PrP. As PrPSc appeared to accumulate in the inner segment at 104 and $118 \mathrm{dpi}$, rootlet morphology changed, and the density of rootlets decreased (Fig. 5h-j). While PrPSc was not usually associated with rootletin, these data suggested that PrPSc accumulation may have damaged the inner segment and its structures including the rootlets.

\section{Detection of PrPSc-associated damage in the outer plexiform layer}

The early accumulation of PrPSc and damage to cone inner segments led us to examine cone photoreceptors more closely. We used dual staining with anti-PrP plus anti-cone arrestin to follow the progression of PrPSc deposition and changes in overall cone morphology over the time course of prion infection from 67 to $162 \mathrm{dpi}$.

In uninfected retina, small dense patches of PrP staining were seen in the OPL just vitread (toward the vitreous) to many of the cone pedicles expressing cone arrestin (Fig. 6a), and this was assumed to be PrPC as it was seen in uninfected mice. Similar staining was also seen at 67 dpi (Fig. 6b). At $104 \mathrm{dpi}$, PrP staining in the OPL was seen basal to some of the cone pedicles similar to uninfected mice. More obvious changes were seen at $118 \mathrm{dpi}$, where cone pedicles were fewer in number and smaller in size (Fig. 6d). PrPSc was abundant in the IS region on both cones and rods, and PrPSc staining in the OPL was both punctate and diffuse and appeared to be independent of cone pedicles (Fig. 6d). At 131 and $162 \mathrm{dpi}$, PrPSc staining in IS and OPL remained strong and was similar to $118 \mathrm{dpi}$. However, at these times, most cone pedicles were gone, and the ONL showed thinning due to a large loss in both cone and rod cell nuclei (Fig. 6e, f). These data suggested that PrPSc deposition in the IS and OPL regions might have induced pathogenic effects resulting in death of both cones and rods.

\section{Loss of cone pedicles and rod spherules visualized by GLUT1 staining}

Glucose transporter 1 (GLUT1) is known to be an excellent marker for cell surface visualization in tissues. Therefore, we used anti-GLUT1 and anti-PrP dual staining to study the details of PrP localization relative to cone pedicles and rod spherules in the OPL area following prion retinal infection. Prior to prion infection, cone pedicles were detected as triangular dark shaped spaces outlined by GLUT1, and just vitread to many of these pedicles a patch of clustered coarse PrPC staining was observed (Supp Fig. 1a). In addition, in the same figure, numerous rod cell endings, i.e. spherules, were also seen, and these appeared to be smaller rounded dark shapes outlined by GLUT1 mainly sclerad (toward the sclera) to cone pedicles (Additional file 1: Fig. 1a). Following prion infection at $118 \mathrm{dpi}$, cone pedicles were difficult to recognize or had disappeared and rod spherules were decreased in number and size (Additional file 1: Fig. 1b). Later, at $153 \mathrm{dpi}$, most of the spherules and pedicles were missing, and all the photoreceptor layers (OS, IS, ONL, OPL) were degenerated (Additional file 1: Fig. 1c). These results demonstrated progressive damage to both rods and cones associated with the presence of PrPSc deposition sclerad to and within the OPL.

\footnotetext{
(See figure on next page.)

Fig. 7 In uninfected retina, PrPC expression is concentrated at the base of cone pedicles. a In the OPL, PrPC (yellow arrowheads) staining is present at the base of cone pedicles highlighted with anti-cone arrestin (arrows). b Electron micrograph (TEM) of the OPL showing a cone pedicle (cp), with multiple round mitochondria $(\mathrm{m})$ and three ribbon synapses (arrows). A yellow dotted line surrounds an estimated region of PrPC from a, which contains many dendritic processes from bipolar and horizontal cells. Some dendrites synapse at ribbons (yellow arrowheads) or make flat contact type synapses (magenta arrowhead) with cone pedicles. Ribbon synapses (arrows) are also visible in rod spherules (r). c Confocal z-stack of uninfected retina shows gross relationship of PrP to rod bipolar cells (PKCa) and horizontal cells (Calbindin). $\mathbf{d}-\mathbf{h}$ A high magnification single $0.130 \mu \mathrm{m}$ optical section taken from area in box in panel $\mathbf{c}$, shows PrP is not associated with PKCa and that some calbindin-positive processes (arrow) lie within the PrP-positive area, but association is not clear. i Confocal z-stack image of retina stained for cone bipolar cell dendrites (SCGN), ribbons (CtBP2) and PrP, shows a dense patch of PrPC vitread to a cluster of short ribbons (box) in a cone pedicle. j-I A single $0.130 \mu \mathrm{m}$ optical section taken from within the box in panel e shows PrPC in close association with SCGN-positive dendrites, and some colocalization is seen as white (arrows). Scale bar in $\mathbf{a}=10 \mu \mathrm{m}, \mathbf{b}=1 \mu \mathrm{m}, \mathrm{c}=2 \mu \mathrm{m}, \mathrm{d}=1 \mu \mathrm{m}, \mathrm{i}=4 \mu \mathrm{m}, \mathrm{j}=0.5 \mu \mathrm{m}$
} 


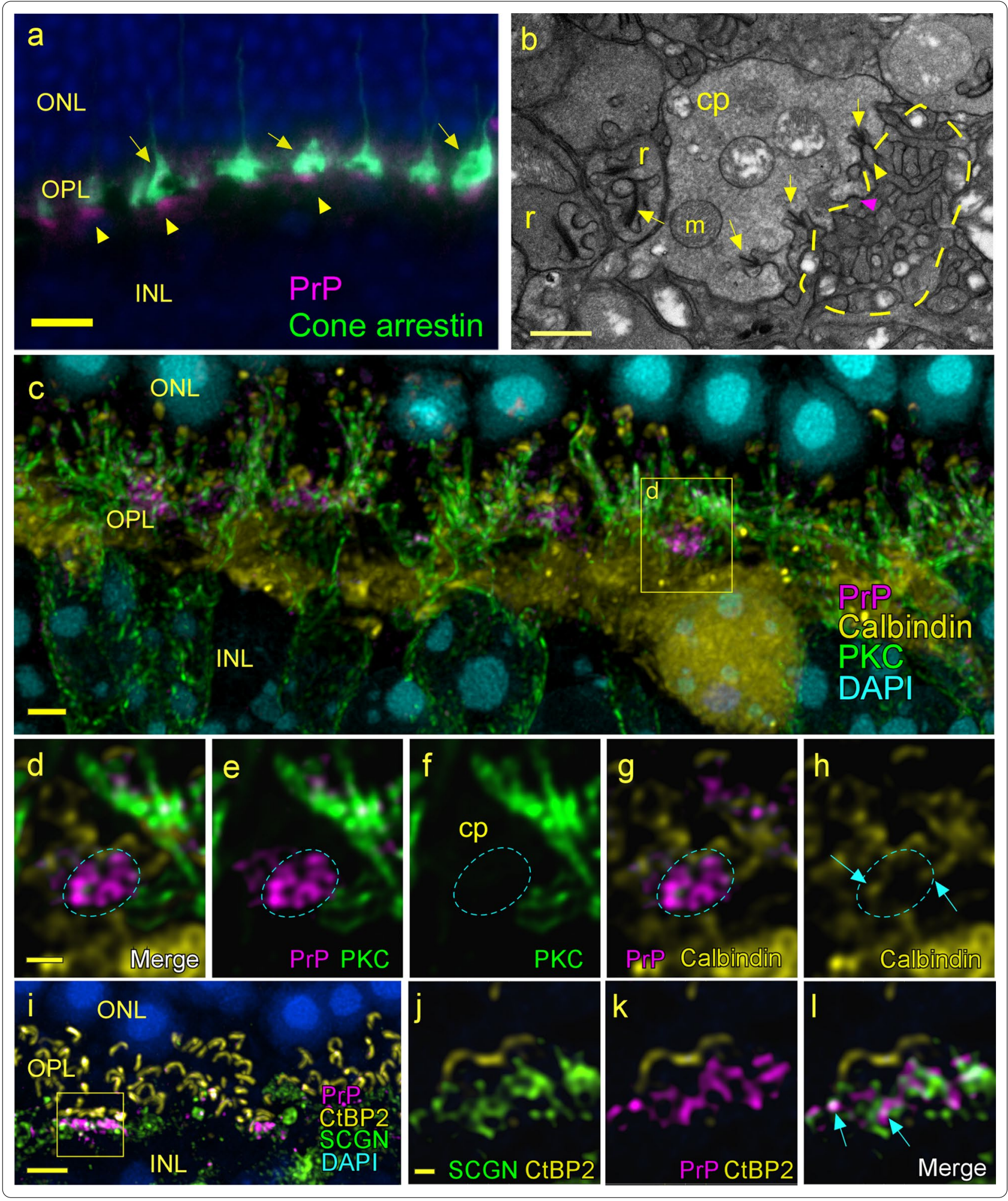




\section{Comparative detection of PrP, ribbon synapses and other structures in uninfected retina}

In the photoreceptor layer bordering the OPL, cone and rod photoreceptor cells are connected with processes from horizontal cells and rod or cone bipolar cells to form ribbon synapses, which have unique electrophysiological and morphological features [36]. Initially we compared the locations of several of these structures in uninfected mice to determine their normal morphology, as observed by both confocal and electron microscopy. Dual staining of an uninfected mouse for cone arrestin and PrP showed PrPC located in large dense clusters vitread to cone pedicles (Fig. 7a). Electron microscopy of the OPL demonstrated rod spherules with single large ribbon synapses and cone pedicles containing multiple short ribbon synapses (Fig. 7b). Notably, comparisons of EM and light microscopy images suggested that areas of intertwined dendrites from bipolar and horizontal cells (Fig. 7b) corresponded to the clustered areas of PrPC seen in Fig. 7a.

In order to understand the association of PrPC with these structures, uninfected retina was stained simultaneously with antibodies against $\operatorname{PrP}$ and proteins expressed by horizontal and bipolar cells (Fig. 7c-f). Confocal microscopy analysis of full z-stacks and individual $130 \mathrm{~nm}$ optical sections was used to reveal the relative locations of the processes and PrP. Dendrites of rod bipolar cells were marked with anti-PKC $\alpha$ and although they were present very near the PrP-stained area beneath cone pedicles, they were not directly associated with $\operatorname{PrP}$ (Fig. 7c, d). Likewise, Calbindin-positive horizontal cell processes were not clearly associated with the dense clusters of PrP (Fig. 7c-h). Next, we triple-stained with anti-PrP, anti-CtBP2, a marker for ribbons and antiSecretagogin, a protein expressed in 8 of the 12 types of cone bipolar cells $[13,42]$. In this experiment, dendrites of cone bipolar cells expressing secretagogin (SCGN) showed a close association with PrPC (Fig. 7i-l). These results suggested that PrPC is highly expressed very near cone pedicles and thus may explain the early accumulation of PrPSc in cones versus rods.

\section{Damage to ribbon synapses seen by staining with anti-CtBP2}

Using dual staining immunofluorescence combining anti-PrP with anti-CtBP2 antibodies specific for ribbon structures, we studied the development of PrPScassociated alterations on ribbon synapse components over time after prion infection. In both uninfected and 82 dpi retinas, ribbon synapses were seen sclerad to the OPL as a continuous band of linear or horseshoe-shaped structures, and $\operatorname{PrP}$ was mostly in bunched loose aggregates vitread to the lower-most ribbons (Fig. 8a, b). At $104 \mathrm{dpi}$, ribbons appeared to be similar to $82 \mathrm{dpi}$, but $\operatorname{PrP}$ staining was slightly more prominent in the ribbon area than previously (Fig. 8c). At $118 \mathrm{dpi}$ (Fig. 8d), ribbons were significantly decreased in number (Fig. 8l), and $\mathrm{PrP}$ was deposited among the ribbons rather than below them (Fig. 8d, j) compared to uninfected retina and earlier timepoints. This PrP was very likely PrPSc as staining was not seen in this location in uninfected retina. Interestingly, at higher magnification, small accumulations of PrPSc were detected within the horseshoe-like curves of many of the ribbons (Fig. 8j, k). Moreover, PrPSc accumulations were never found directly on ribbons, which is where synaptic vesicles are located. This suggested that PrPSc was on the postsynaptic side of the ribbon synapses (Fig. 8j). At later time points, 131, 153 and 163 $\mathrm{dpi}$, ribbons were progressively destroyed, as were the cone and rod cell nuclei in the ONL (Fig. 8e-g, l). Disappearance of ribbons correlated with significant increases of PrPSc at 118 dpi (Fig. 81 vs m). Thus, the appearance of $\operatorname{PrP}$ within the ribbon horseshoes correlated with the onset of loss of ribbon synapses and suggested this PrPSc deposition might be responsible for this damage.

\footnotetext{
(See figure on next page.)

Fig. 8 Timecourse of disappearance of ribbon synapses in OPL. a, $\mathbf{h}$ Uninfected retina shows many horseshoe-shaped ribbons stained with CtBP2 (green), sclerad to PrPC (magenta) densities. Most ribbons are not associated with PrPC see panel h. b, i At 82 dpi, the number of ribbons is similar to uninfected, but at cone pedicles PrP appears brighter and more punctate suggestive of new PrPSc accumulation. c 104 dpi retina appears similar to 82 dpi. d, j 118 dpi, ribbons in OPL appear disorganized and are significantly reduced in number, and PrPSc deposits are visible within horseshoe arcs, but not touching, most ribbons (j, yellow arrows). e, k At 131 dpi PrPSc accumulation has peaked and most ribbons have disappeared. Remaining horseshoe-shaped ribbons show association with PrPSc (k, yellow arrow). f, g At late dpi, ONL has thinned dramatically, few ribbons remain, PrPSc is widespread. I Graph shows \# of ribbons/ $\mu$ m of OPL of scrapie infected retina at dpi vs uninfected. Each dot represents count from one field of view. $\mathbf{m}$ Quantitation of PrP (magenta) fluorescence integrated intensity/ $\mu \mathrm{m}$ of OPL of scrapie infected retina at dpi vs uninfected. Each dot represents integrated intensity measurements from one field of view. Lines median value, $n s$ not significant, ${ }^{*} p<0.05,{ }^{* *} p<0.01,{ }^{* * *} p<0.001$, ${ }^{* * * *} p<00.0001$. Statistics were calculated using one-way ANOVA with multiple comparisons. Scale bars: $\mathbf{a}-\mathbf{g}=4 \mu \mathrm{m} ; \mathbf{h}-\mathbf{k}=1 \mu \mathrm{m}$
} 

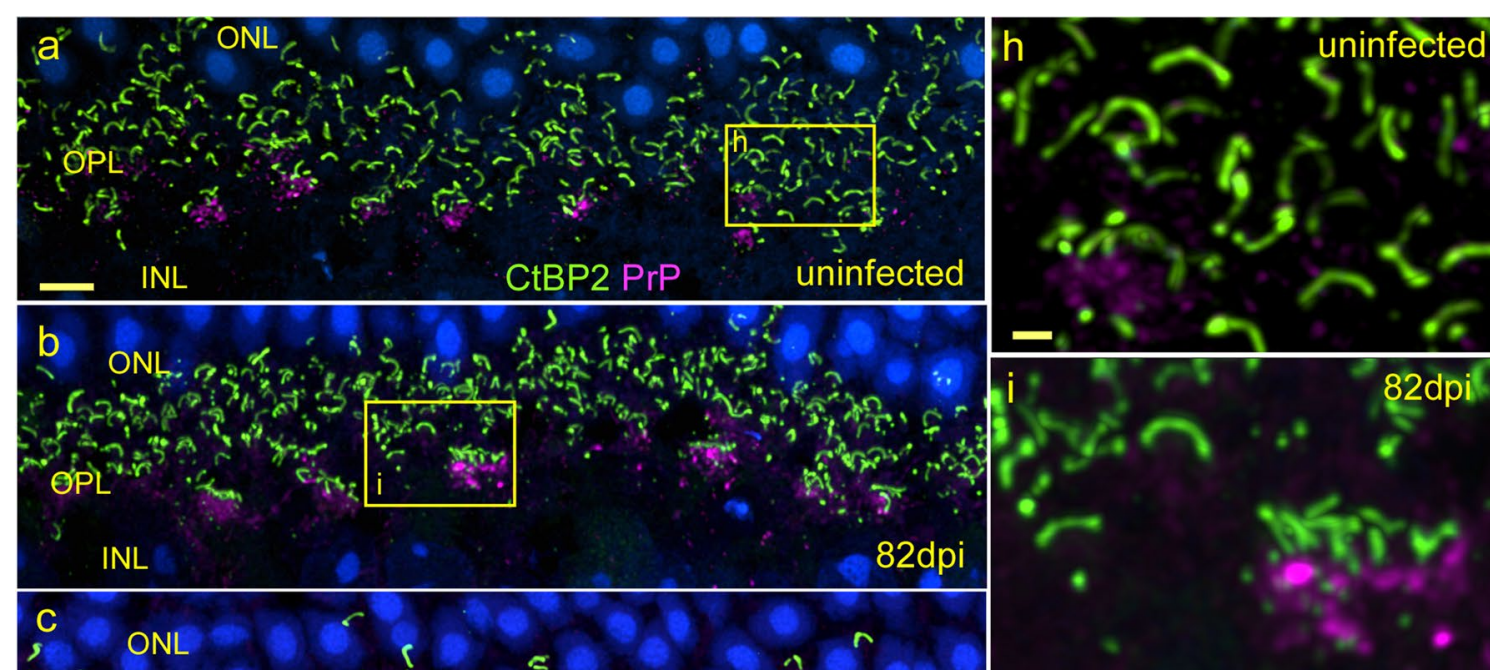

C ONL

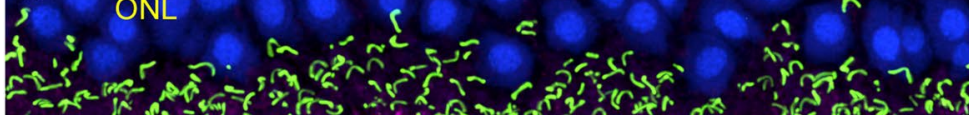

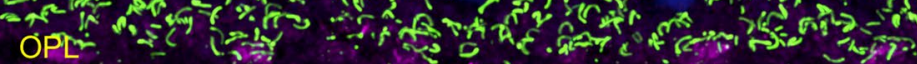
INL

104dpi
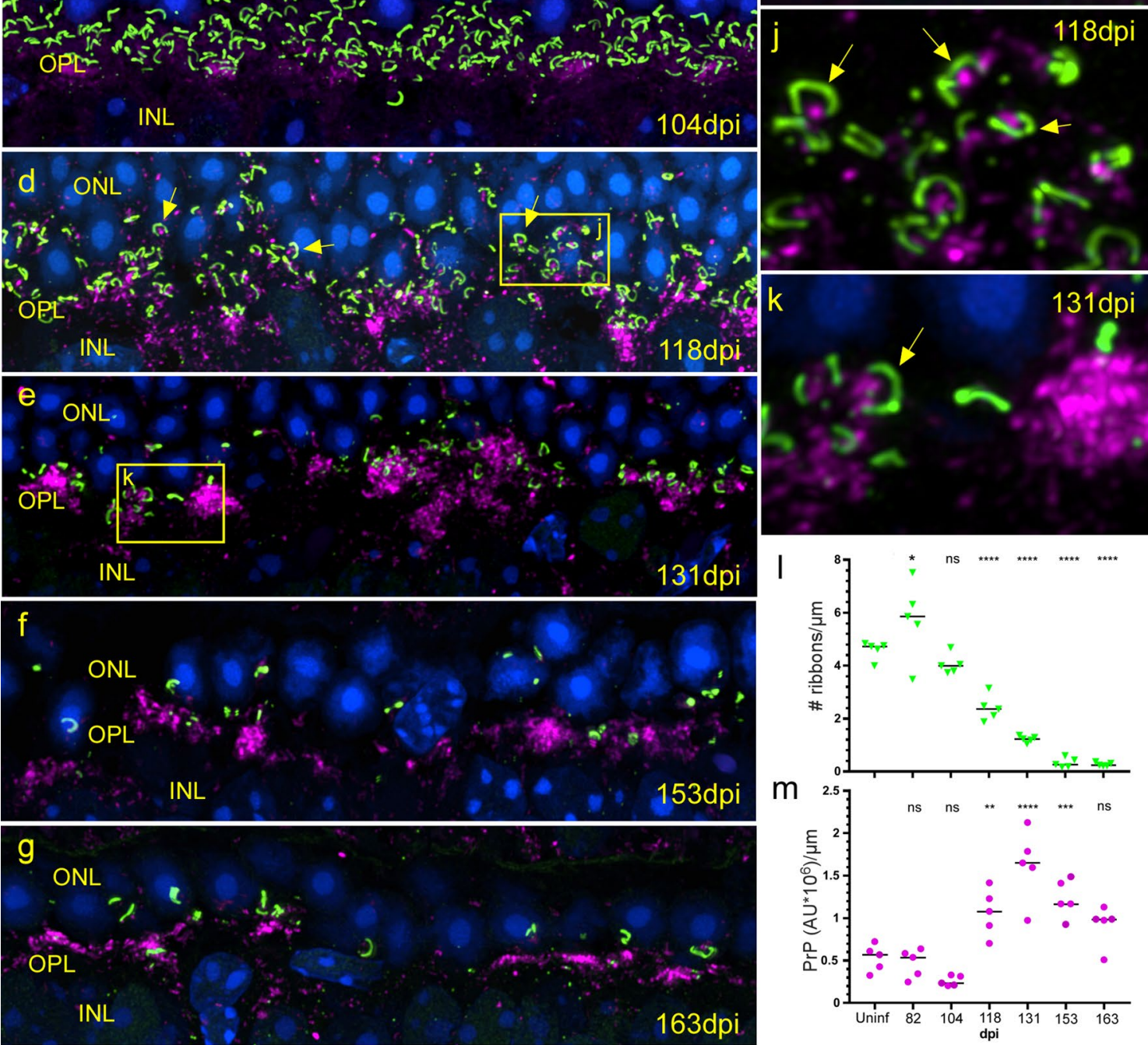


\section{Association of PrPSc to rod and cone bipolar cells near ribbon synapses}

The location of PrPSc, adjacent to but not touching ribbons, suggested these deposits were associated with the postsynaptic portion of the ribbon synapses. Dendrites of rod and cone bipolar cells and horizontal cells are known to make up the postsynaptic elements of ribbon synapses in the OPL [36]. Here, investigation of the possible interactions of PrPSc with rod bipolar cells was done by dual staining with anti-PrP and anti-PKC $\alpha$, which is specific for rod bipolar cells.

In uninfected and $82 \mathrm{dpi}$ prion-infected mice, cell bodies of rod bipolar cells were seen just vitread to the OPL and dendritic processes from these cells extended up through the OPL to the area of the cone pedicles and rod spherules (Fig. 9a, b). PrP was detected mostly in the OPL sclerad to the rod bipolar cells (Fig. 9a, b). However, starting at $104 \mathrm{dpi}$ and continuing at $118 \mathrm{dpi}$, PrP deposits were seen in a new location, at the tips of the dendritic processes of the rod bipolar cells that synapse with ribbons (Fig. 9c, d). This was also visible in more detail by confocal microscopy (Compare Fig. 9f vs g). Because deposits in these locations were only seen after prion infection, they were thought to be PrPSc.

At higher magnification this PrPSc had the appearance of beads on a string extending along the processes (Fig. 9h-k), and PrPSc seemed to displace or overlap the original PKC $\alpha$ staining of the processes. This was specific for infected retinas at the 104-118 dpi time-points (Fig. 9c, d, g) and was not seen in the uninfected or $82 \mathrm{dpi}$ retinas (Fig. 9a, b). The precise location of PrPSc deposits, at the ribbon synapse on the tips of rod bipolar cell dendrites, was confirmed using confocal analysis of a section triple stained for PrP, PKC $\alpha$ and CtBP2 (Fig. 9l). At late times in disease (131 dpi), the majority of the rod bipolar dendritic structures had degenerated (Fig. 9e), however, rod bipolar cell bodies appeared to be decreased only by about 50\% starting at $118 \mathrm{dpi}$ and they did not decrease further after this time (Fig. 10a-e). Axons, dendrites and dendritic boutons disappeared along with the cell bodies. This was in marked contrast to the rods and cones themselves which were mostly eliminated at this time post-infection.

The dendrites of cone bipolar cells synapse mainly with cone photoreceptor cells in the OPL and can be marked using anti-Secretagogin (SCGN) antibody [13]. To check for an association of PrPSc deposits with cone bipolar cell dendrites we triple-stained retina for PrP, SCGN and CtBP2 (Fig. 11a-d). As was also shown in Fig. 7, PrPC in uninfected mice was found to be in close association with SCGN-positive dendrites under clusters of short ribbons (Fig. 11a). Likewise, single confocal sections, showed PrPC intermingled among SCGN-positive cone bipolar cell dendrites (Fig. 11b). In infected mice at 104 and $118 \mathrm{dpi}$, staining with anti-PrP antibody D13 revealed an increase in PrPSc among SCGN-positive dendrites where they make synaptic connections with cone pedicles (Fig. 11a-f), and this deposition was coincident with the previous finding of PrPSc on the tips on rod bipolar cell dendrites beneath the horseshoe-shaped ribbon synapses present in rod photoreceptors (Fig. 9h-l). The timing and location of this increase in PrP staining suggested these deposits were likely to be the disease-associated form of PrP. Despite the destruction of most ribbon synapses in cones and the disappearance of cone bipolar cell dendrites, the number of SCGN-positive cone bipolar cells did not decrease during disease (Fig. $11 \mathrm{~g}-\mathrm{k}$ ). Thus, both rods and cones were uniquely sensitive to prion-induced damage compared to other retinal neurons.

\section{Identification of PrPSc near horizontal cell dendrites and boutons}

Along with dendritic processes from rod or cone bipolar cells, dendrites from two horizontal cell neurons (HC) make up the triad of processes that invaginate the photoreceptor at each ribbon synapse [36]. Therefore, HC were also studied during prion retinal infection using dual staining with anti-PrP and anti-calbindin, which

\footnotetext{
(See figure on next page.)

Fig. 9 PrPSc accumulation at tips of rod bipolar cell dendrites and disappearance of dendrites. Epifluorescent microscopy analysis. a In uninfected retina, PrP (magenta) (blue arrowhead) and PKCa-positive rod bipolar cells (green) are seen near each other in the OPL. Many boutons (blue arrow) are present at dendritic tips of rod bipolar cells. b At 82 dpi, OPL appears similar to uninfected. Asterisk marks a rod bipolar cell body in INL. c At 104 dpi, PrP staining appears at dendritic tips. d At 118 dpi, most PKCa-positive dendrites display PrP at tips of processes (boutons) (arrow). e By 131 dpi most dendrites and dendritic boutons have disappeared, bipolar cell bodies remain (arrow), and PrPSc is distributed in large aggregates. Confocal analysis. f Maximum intensity projection shows PKCa and PrP staining of uninfected retina. Arrows indicate PKCa-positive rod bipolar cells with obvious boutons at the ends of dendrites. $g$ A 118 dpi retina shows PrPSc arranged in bead-like deposits on dendrites, often replacing boutons. Magnification of boxes on left and right are shown below in panels $\mathbf{h}-\mathbf{k}$. $\mathbf{h}$ Confocal image shows association of PrPSc with dendrites and dendritic tips in area of right box from $\mathbf{g}$. i-k Confocal images show merged, PrP and PKC staining of left box area in $\mathbf{g}$. I In a high magnification of confocal image, anti-CtBP2 antibody marks ribbons (arrows) and confirms PrPSc deposits (magenta) on tips of dendrites (green) invaginating, but not touching, ribbons. Scale bars: $\mathbf{a}-\mathbf{e}=5 \mu \mathrm{m} ; \mathbf{f}, \mathbf{g}=3 \mu \mathrm{m} ; \mathbf{h}-\mathbf{k}=2 \mu \mathrm{m} ; \mathbf{I}=0.5 \mu \mathrm{m}$
} 

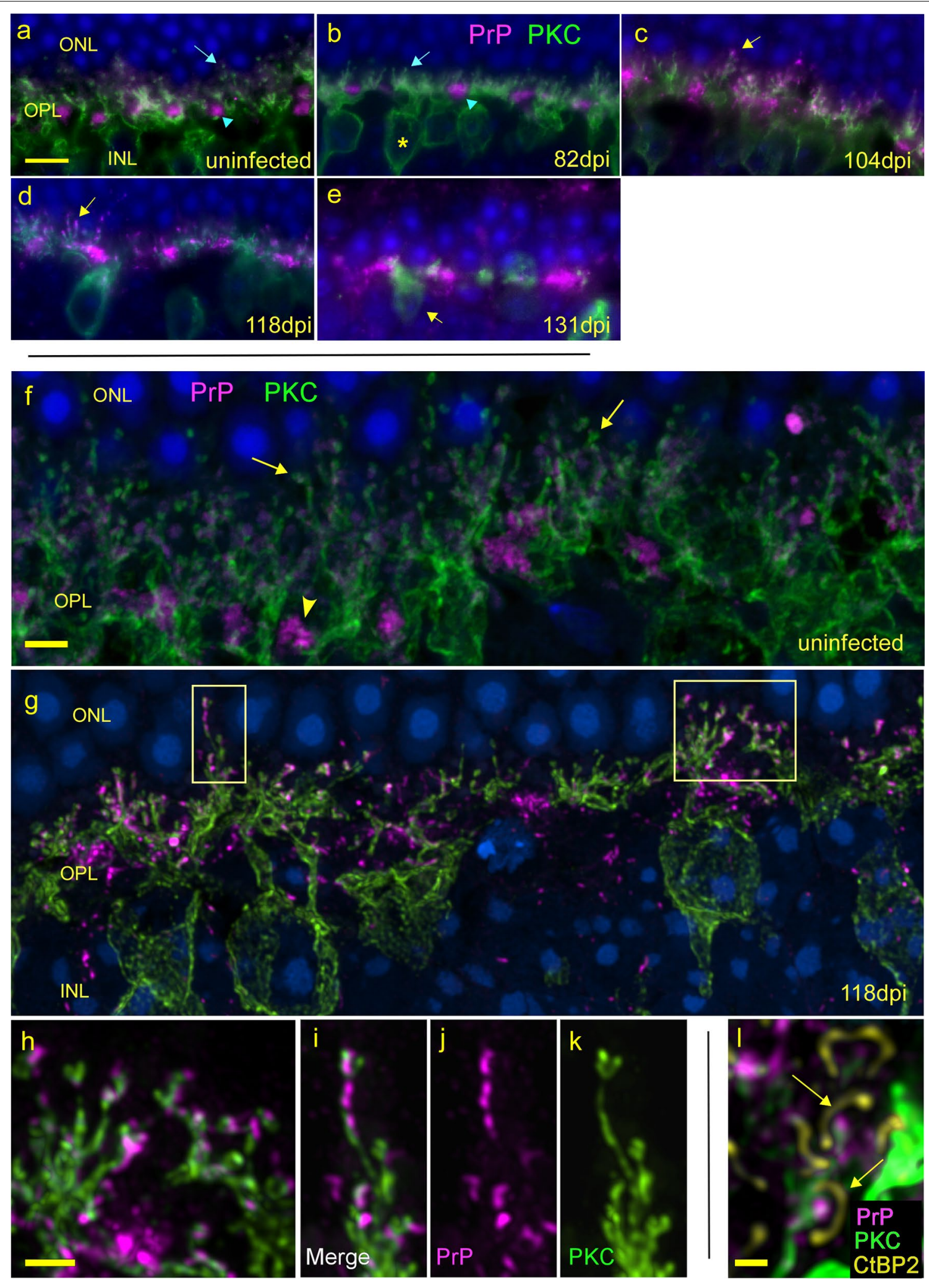

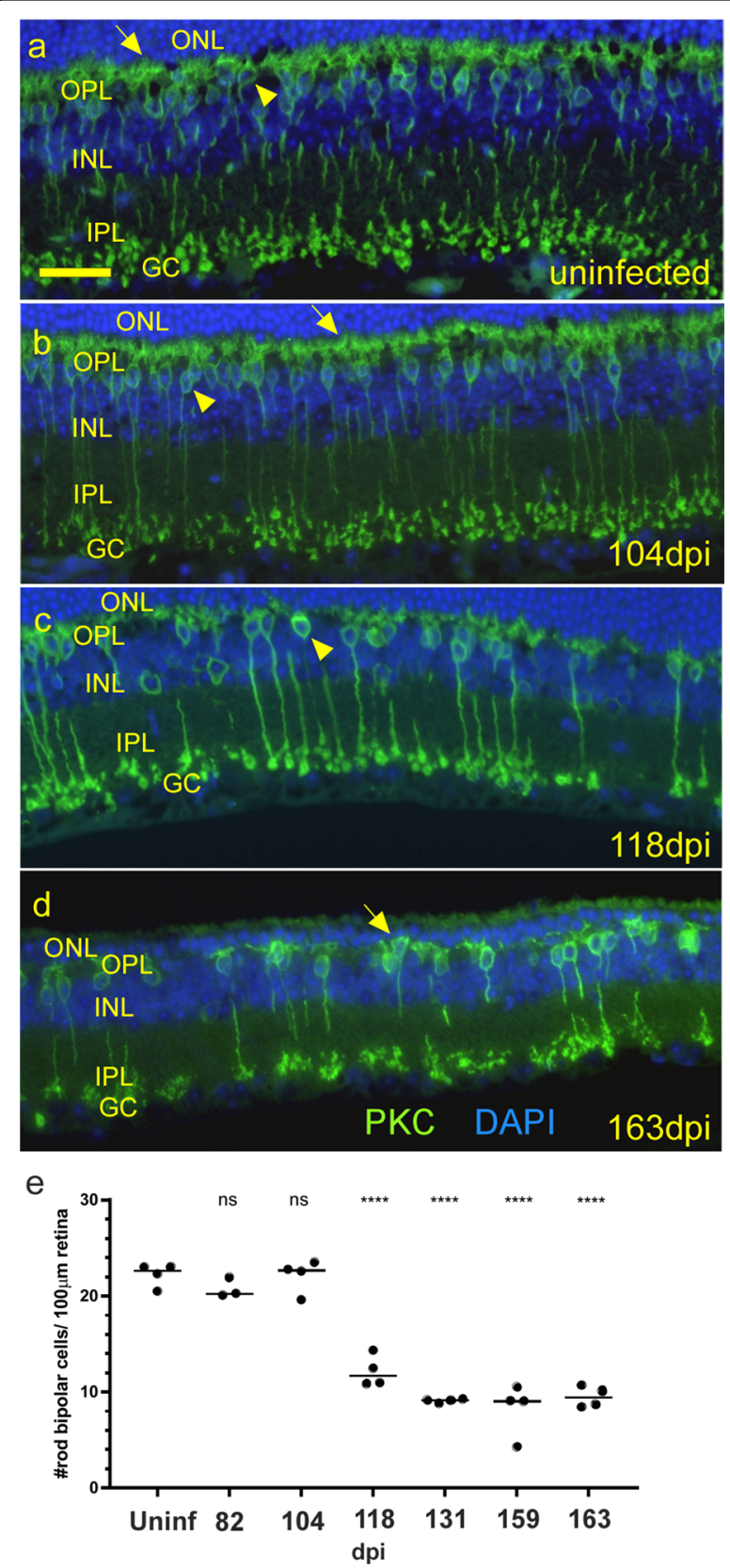

Fig. 10 Changes in rod bipolar cells during infection. a anti-PKCa staining (green) in an uninfected mouse shows normal distribution and morphology of rod bipolar cells. Numerous dendrites (arrow) reach upward to synapse with photoreceptors in ONL from each cell body (arrowhead). b At 104 dpi rod bipolar cells appear similar to uninfected mouse. c By 118 dpi the number of bipolar cells has dropped to about half vs uninfected and some cell bodies have few if any associated dendrites (arrowhead). $\mathbf{d}$ Late in disease, at 163 $\mathrm{dpi}$, rod bipolar cell number is significantly reduced compared to uninfected retina, and few dendrites reach into OPL (arrow). e The number of rod bipolar cells per $100 \mu \mathrm{m}$ of retina over time. Each dot represents counts from one field of view, line is median, ns = not significant, ${ }^{*} p<0.05,{ }^{* *} p<0.01,{ }^{* * *} p<0.001,{ }^{* * * *} p 0.0001$ statistics by one-way ANOVA with multiple comparisons test. Scale bar in $\mathbf{a}=20 \mu \mathrm{m}$ is expressed on the cell body, dendrites and boutons of $\mathrm{HC}$. In uninfected mice, $\mathrm{HC}$ bodies were vitread to the OPL, and processes and boutons were mostly in the OPL (Fig. 12a, b), and the clumped aggregates of PrP seen previously did not associate with either the $\mathrm{HC}$ or their processes. After scrapie infection at $104 \mathrm{dpi}, \mathrm{HC}$ bodies, processes, and boutons were unchanged (Fig. 12c, d). As expected, the PrP clumps seen previously in uninfected mice were missing, and $\operatorname{PrP}$ was now mostly disseminated in small punctate or linear deposits in the OPL which were near, but slightly separated from the HC boutons (Fig. 12c, d). This difference in PrP morphology suggested that this material was PrPSc. At $118 \mathrm{dpi}$, the $\mathrm{HC}$ boutons were less distinct and PrPSc was still similar to $104 \mathrm{dpi}$ (Fig. 12e, f). There was still no association between HC bodies and PrP. This relationship was confirmed using confocal analysis of a triple stained section (Fig. 12i-l), where at high magnification, it was evident that calbindin-positive boutons did not contact PrPSc (Fig. 12j), whereas PrPSc was in contact with PKC $\alpha$, the marker for rod bipolar cells (Fig. 12k). At 131 and 153 dpi the HC processes and the entire OPL region was atrophied, and damage appeared to be severe. However, PrPSc deposits were more consolidated and surprisingly, most $\mathrm{HC}$ bodies were intact (Fig. 12g, h, m).

In summary, at 118 dpi there was evidence of deposition of PrPSc in the OPL, at the ribbon synapses of rod photoreceptors. While PrPSc was not directly in contact with the presynaptic ribbons (CtBP2), it was associated with the postsynaptic elements of the synapses. PrPSc was found on the dendritic boutons of rod bipolar cells $(\mathrm{PKC} \alpha)$, where they invaginated ribbons synapses and on cone bipolar cell dendrites (SCGN) adjacent to ribbon synapses. HC boutons (Calbindin) did not show accumulations of PrPSc. These data suggested that prion infection and PrPSc deposition on rod and cone bipolar cell processes might have a toxic effect on ribbon synapses leading to damage and death of both rods and cones.

\section{Electron microscopy of outer plexiform layer confirms loss of synapses}

Analysis of the OPL by transmission electron microscopy confirmed many of the findings determined by confocal microscopy. TEM was advantageous in that it allowed a view of all structures simultaneously. Sections from uninfected mice showed many photoreceptor axon terminals (rod spherules and cone pedicles) containing ribbon synapses, most were connected to a triad of invaginating dendritic processes from horizontal and bipolar cells. Rod spherules contained a single large, round mitochondrion and a ribbon synapse, while cones contained multiple small mitochondria and 3-5 ribbon synapses (Fig. 13a). Early in disease (104 dpi), overall morphology 
was similar to uninfected mice (Fig. 13b), however in some cone pedicles, swollen, dystrophic dendritic processes were noted around ribbon synapses, suggesting that cone photoreceptors were beginning to degenerate (Fig. 13b). At later timepoints (Fig. 13c-f), typical triad ribbon synapses were rarely noted and both rod spherules and cone pedicles, if present, were often dystrophic. Frequent whorl structures, suggestive of autophagosomes, were noted adjacent to, or in place of ribbon synapses in both rods and cones. In short, these ultrastructural findings supported the conclusions from fluorescent microscopy that at late timepoints all elements of ribbon synapses had degenerated.

\section{Discussion}

In the present study, we followed the timing and location of PrPSc deposition in retina following intracerebral prion injection in mice using immunofluorescence and electron microscopy. The earliest PrPSc deposits in retina were found at $67 \mathrm{dpi}$ and were located in the IS region of cone photoreceptor cells. At 104 dpi PrPSc could be detected adjacent to the cilium, which connects the IS and OS portions of each cone and rod cell. These events were followed by cell swelling and alteration of organelles, such as rootlets, at $104 \mathrm{dpi}$, and progressive loss of cone and rod cell nuclei in the ONL starting at $118 \mathrm{dpi}$. Similar events with the exception of swelling were seen in rods on a time course about 14 days behind cones.

The association of PrPSc with cilia may be an important clue to the pathogenic process of prion infection in retina. This abnormal accumulation might interfere with or damage the ciliary protein transport system between the IS and OS regions of photoreceptors as has been proposed in retinitis pigmentosa and ciliopathies [34, 40]. In support of this mechanism, we found unusual distributions of opsin and cone arrestin (Figs. 4, 5, 6), suggesting interference with the normal trafficking of these proteins between the IS and OS.

Beginning at $104 \mathrm{dpi}$, abnormal PrPSc deposition was also detected in the OPL region near and within the cone pedicle and rod spherules. Although this process appeared to begin later than the process in the IS region, it still coincided with the detection of photoreceptor cell pathology at 104-118 dpi and thus might play a role in damage and death of rods and cones. In the OPL of uninfected mice, PrP was normally detected on or near the dendrites of cone and rod bipolar cells located vitread to rod spherules and cone pedicles, but after prion infection, PrP detection shifted to sites on the tips of bipolar cell dendritic boutons, where they invaginate rods to form ribbon synapses. Likewise, PrP deposits increased among the dendrites of cone bipolar cells where they synapse with cone pedicles. This different PrP distribution suggested that this material was disease-associated PrPSc. During this same time, starting at 104-118 dpi and continuing up through $153 \mathrm{dpi}$, there was progressive loss of ribbons in rods and cones associated with loss of over $90 \%$ of photoreceptor cone and rod nuclei in the ONL. The mechanism of damage induced by the presence of PrPSc on the tips of bipolar cell dendritic boutons is not clear. However, the accumulation of protein aggregates at sites of synaptic transmission might confound the synaptic transmission process or alter neuritic connectivity $[53,61]$. Similar speculations have been suggested for hippocampal synapses in prion-infected brain

\footnotetext{
(See figure on next page.)

Fig. 11 Association of PrPSc with cone bipolar cells. a Confocal z-stack of an uninfected retina shows secretagogin-positive cone bipolar cell bodies (magenta arrows) and their green dendritic processes associated with PrP (magenta) in dense clusters (yellow arrows) which include short ribbon synapses (yellow). b A single confocal section taken from the box in panel a shows PrP in close association with cone bipolar cell dendrites (green), beneath clusters of short ribbons (yellow) typically found in cone pedicles. Horseshoe-shaped ribbons in rod spherules (blue arrows) are not associated with PrP or SCGN. c In a confocal z-stack, at $118 \mathrm{dpi}$, cone bipolar cell bodies (magenta arrow) appear normal but PrP staining is increased in the OPL. $\mathbf{d}$ A single confocal section taken from the box in panel c shows increase in PrP among the SCGN-positive dendrites with some PrP overlapping SCGN, suggesting colocalization (white arrow). PrP is also present within the horseshoe-shaped ribbon synapses in rods (blue arrows). e, f Widefield images at 104 dpi show numerous examples of PrP clusters localizing with the ends of SCGN-positive dendrites (blue arrows) originating from cone bipolar cells (magenta arrows). $\mathbf{g}$ Number of cone bipolar cells per $\mathrm{mm}$ vs dpi. Each symbol represents the count from one field of view. Different symbols represent different animals. Line represents median. $\mathbf{h}-\mathbf{k}$ anti-Secretagogin stained retina from uninfected and three different dpi show relative numbers of SCGN-positive cells. ns = not significant, statistics by one-way ANOVA with multiple comparisons test. Scale bars: $\mathbf{a}, \mathbf{c}=4 \mu \mathrm{m} ; \mathbf{b}, \mathbf{d}=1 \mu \mathrm{m} ; \mathbf{e}, \mathbf{f}=10 \mu \mathrm{m} ; \mathbf{h}-\mathbf{k}=25 \mu \mathrm{m}$
} 

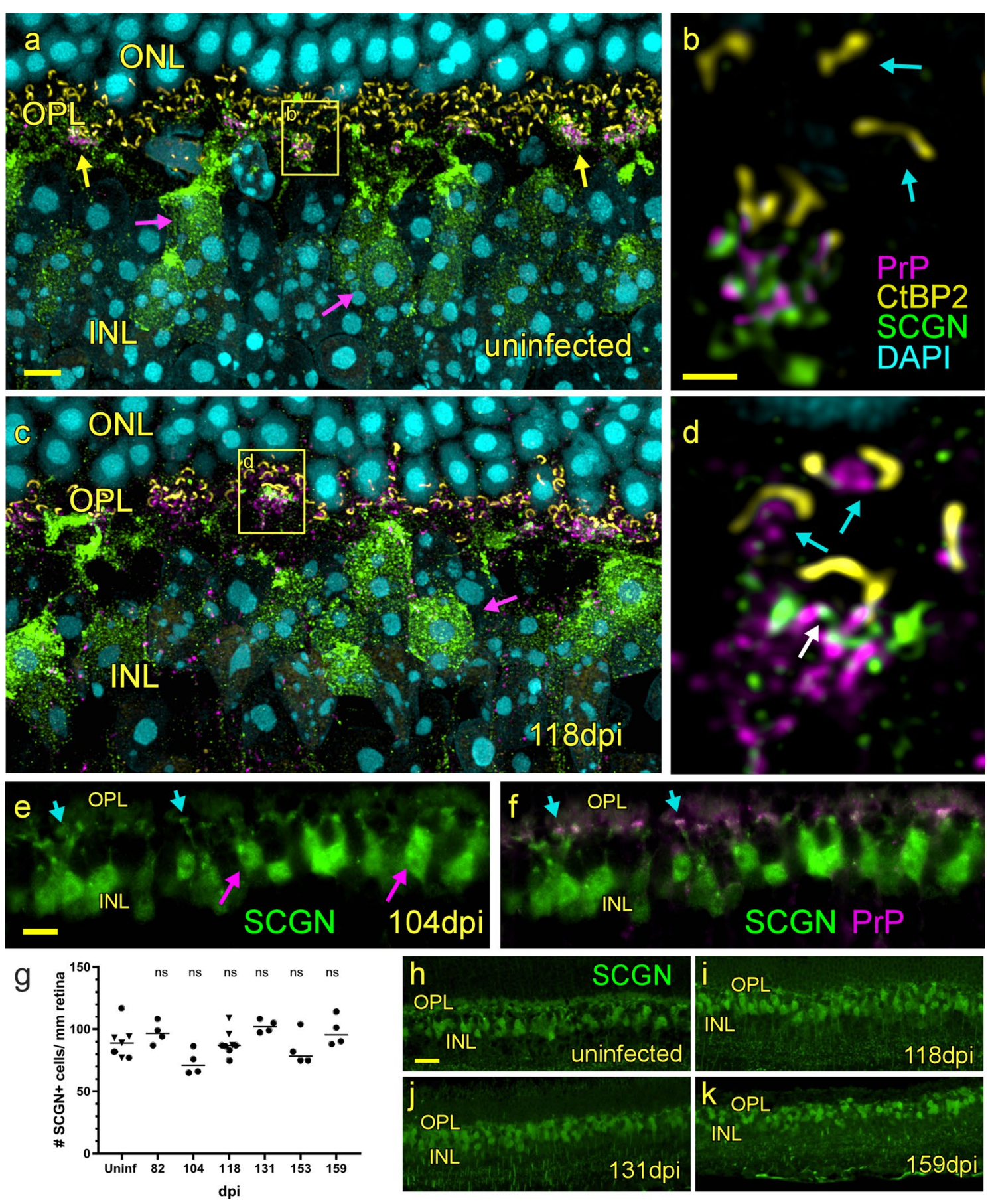
$[12,27,48]$. However, this has not previously been suggested for retinal photoreceptor ribbon synapses, where the molecular components can be visualized in better detail.

Interestingly other nearby retinal neurons were damaged less by prion infection. For example, cell bodies of cone bipolar cells remained constant throughout disease, rod bipolar cell bodies decreased by $50 \%$, and horizontal cell bodies decreased less than $10 \%$. However, dendrites in the outer plexiform layer of all these cells showed significant damage. Ganglion cells and amacrine cells also did not appear to be damaged. These latter two cell types were not specifically stained and counted, but cellularity in the regions where they typically reside appeared to be normal. One explanation for the extreme sensitivity of cone and rod cells to prion infection might be the PrPSc association and blockage of cilia which are not found in the other above-mentioned retinal neurons. Alternatively, the level of PrPC expression in various cell types might also play a role in these differences. In contrast, photoreceptor degeneration was not observed in our studies of prion-infected transgenic mice expressing GPIanchorless PrP, suggesting expression of anchored PrPC on the cell membrane may be critical to PrPSc-induced damage to certain cell types [30].

Another question raised by these results is why the cones preceded rods in the PrPSc deposition and damage process. In some rare retinal degenerations, known as Cone and Cone-rod dystrophies, cones also precede rods in damage and death, however it is more common for rods to begin the degenerative process, as in retinitis pigmentosa $[39,56]$. In other neurodegenerative diseases affecting retina, such as $\mathrm{AD}$ and $\mathrm{PD}$, photoreceptors are not typically affected first and specificity for cones or rods is not clear, though a recent study found accumulations of phosphorylated tau specifically in ageing primate cones $[1,35,44]$. Interestingly, cones make up only $3 \%$ of photoreceptors in mouse retina, so the cone cell specificity in our study was surprising. This could be due to local differences in PrP expression which might influence the timing of PrP conversion to PrPSc. We have not been able to measure differences in normal PrP expression in the IS region of uninfected rods and cones. However, in the OPL region, uninfected mice have high PrPC expression in the dendritic processes of bipolar cells located directly beneath the cone pedicles. These are a mixture of rod and cone bipolar cells which all appear to deposit PrPSc on their dendrites after prion infection, but while there are hundreds of synaptic connections to each cone pedicle, each rod spherule has no more than seven [38]. This difference might increase the efficiency of prion travel to the IS regions of cones vs rods. In addition, prion travel from ganglion cells to cone cells can be direct, whereas intermediate cells, such as amacrine cells, are often involved in connecting ganglion cells to rod bipolar cells [14]. The more direct route to cones might increase the tempo of prion infection, favoring cones over rods.

The damage mechanism(s) seen in prion-infected retina and brain are not well understood [25]. Our earlier studies indicated the presence of apoptotic cells in the ONL after prion infection $[29,54]$. Since these observations were made later in the disease course, these cells were likely to be mostly rods which are $32 \times$ more abundant than cones in mouse retina. However, in our studies using cone opsin to detect cones, damaged PrPSc-positive cones in the IS region at 104 and 118 dpi were swollen suggesting a necrotic rather than apoptotic cell death process (Figs. 4, 5, 13). Interestingly, this same pathology preceding cone necrosis is similar to previous results of Murikami et al. [37] studying the human retinitis pigmentosa rd10 mutation in a mouse model and in human retinitis pigmentosa patients.

\footnotetext{
(See figure on next page.)

Fig. 12 Timecourse and confocal analysis of PrP association with horizontal cells. a,b In uninfected mouse retina, anti-calbindin labels horizontal cell bodies (yellow arrow), dendrites (blue arrows) and boutons (arrowheads). PrPC magenta densities (long yellow arrow) are surrounded by horizontal cell boutons and dendrites. c, d At 104 dpi, calbindin-positive boutons (arrowheads) are near, but not touching, new PrPSc deposits (magenta). e, f At $118 \mathrm{dpi}$, PrPSc (magenta) is more widely distributed, and number of boutons is significantly reduced. PrPSc is near, but not in contact with horizontal cell components. $\mathbf{g}$, h At later timepoints 131 and $153 \mathrm{dpi}$, ONL is thinned due to loss of photoreceptor nuclei. Few, if any, horizontal cell boutons are present. Large PrPSc deposits (arrow) are visible in the OPL, but not in horizontal cell bodies. i At very high magnification, a 118 dpi retina shows a PKCa-positive rod bipolar cell dendrite (green) near calbindin-positive (yellow) horizontal cell boutons (blue arrows). j A PrPSc deposit (magenta) is very close to, but not touching the horizontal cell boutons (blue arrowhead). $\mathbf{k}$ In a merge of three channels the white color indicates the association of a PrPSc deposit (magenta) with the dendritic tip of a rod bipolar cell (green). I Cartoon depicts preceding three panels, with addition of presumed location of rod spherules (rs) and ribbons (r). $\mathbf{m}$ Surprisingly, the number of horizontal cell bodies does not change significantly over time. Scale bars: $\mathbf{a}, \mathbf{c}, \mathbf{e}, \mathbf{g}, \mathbf{h}=5 \mu \mathrm{m} ; \mathbf{b}, \mathbf{d}, \mathbf{f}=2 \mu \mathrm{m} ; \mathbf{i}-\mathbf{I}=\mathbf{0 . 5} \mu \mathrm{m}$
} 

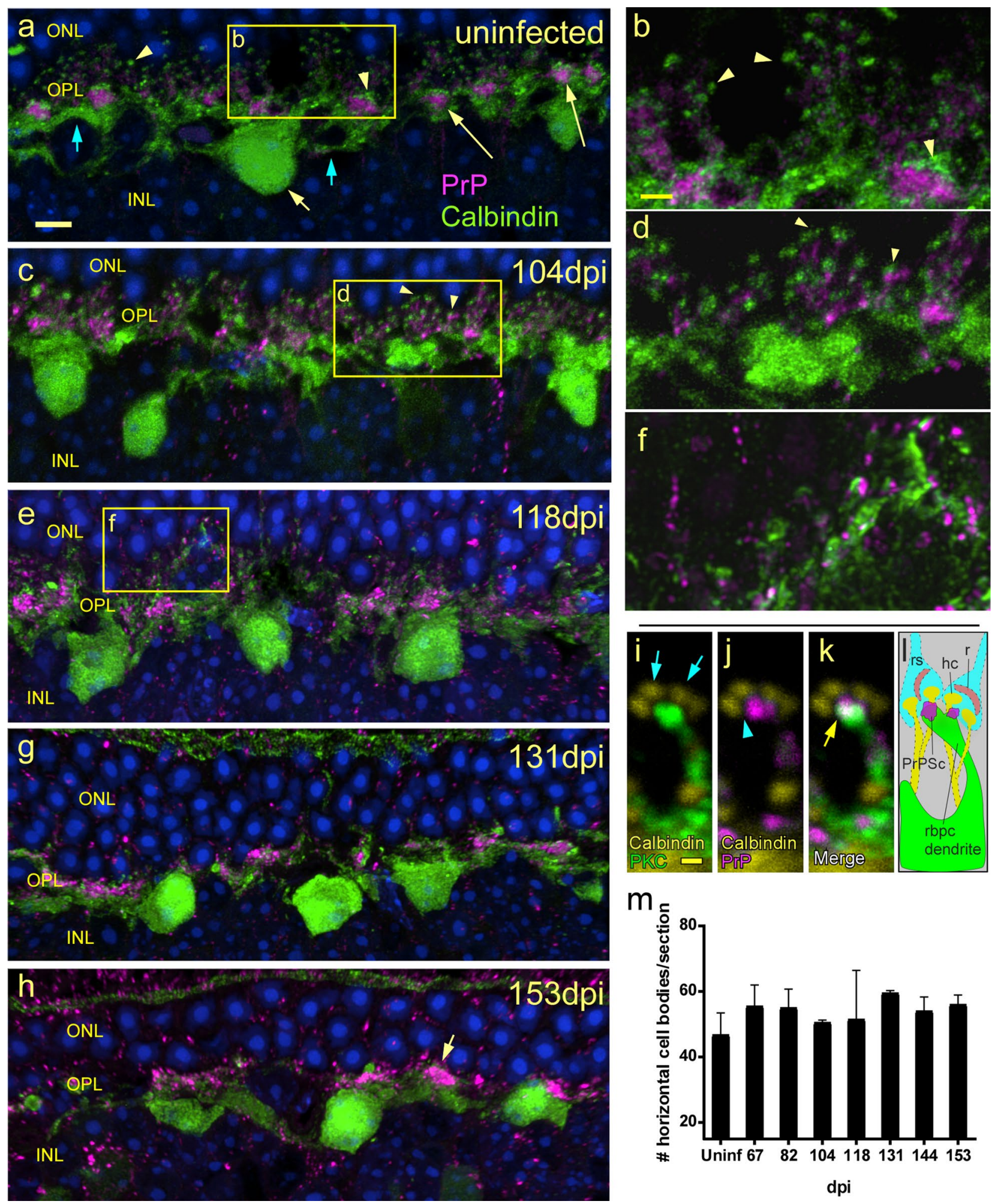

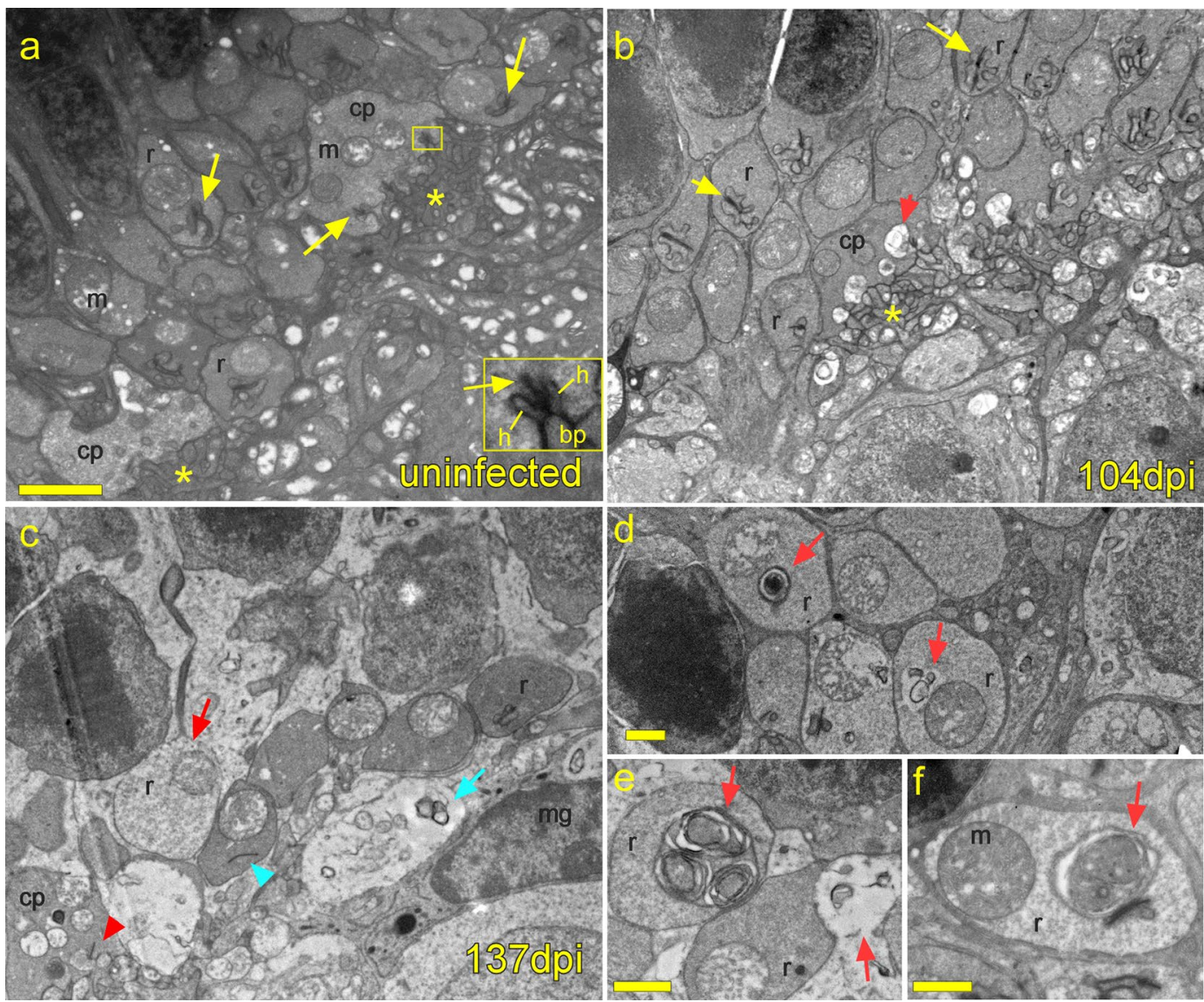

Fig. 13 Transmission electron microscopy shows timeline of changes in outer plexiform layer. a Uninfected retina shows numerous rod spherules ( $r$ ) each containing a single ribbon synapse (arrow) and mitochondrion ( $\mathrm{m}$ ). Cone pedicles (cp) contain multiple ribbon synapses (yellow arrows) and mitochondria (m). Inset shows magnified cone ribbon synapse with ribbon (arrow), and a typical triad consisting of two invaginating horizontal cell processes ( $h$ ) and one bipolar cell process (bp). Many bipolar and horizontal cell processes are present vitread to cone pedicles (asterisks). b At 104 dpi, most rod spherules appear normal with ribbon synapses present. A cone pedicle (cp) at center, has swollen dystrophic dendritic processes at ribbon synapses (red arrow). Bipolar and horizontal cell processes are present beneath the pedicle (asterisk). c At 137 dpi the OPL appears disorganized with abnormal rod spherules (red arrow), a floating ribbon synapse (blue arrowhead) without invaginating dendritic processes, autophagic whorl (blue arrow) and a dystrophic dendrite (red arrowhead) at a ribbon synapse in a cone pedicle. Microglial cell (mg). $\mathbf{d}, \mathbf{e}, \mathbf{f}$ Examples of autophagic-like whorls (red arrows) in rod spherules at $137 \mathrm{dpi}$. Scale bars $\mathbf{a}-\mathbf{c}=2 \mu \mathrm{m} ; \mathbf{d}, \mathbf{e}, \mathbf{f}=1 \mu \mathrm{m}$

\section{Conclusions}

The present experiments report two new areas of deposition of abnormal disease-associated PrPSc in prioninfected retina. These regions both involve photoreceptor cone and rod cells which then go on to die as a part of the disease process. The location of the PrPSc deposition suggests that the damage mechanisms may involve interruption of the ciliary transport pathways of molecules between the inner and outer segments of PR cells as well as damage to ribbon synapses found in the synaptic endfeet of rods and cones near the OPL. Possible synergy and specificity between these two mechanisms remains to be worked out. These mechanisms might be active in other human retinal degenerative diseases where protein misfolding occurs, such as retinitis pigmentosa and prion-like diseases, such as $\mathrm{AD}$ and $\mathrm{PD}$. 


\section{Supplementary information}

The online version contains supplementary material available at https://doi. org/10.1186/s40478-021-01120-x.

Additional file 1: Fig. 1 Cone pedicles and rod spherules disappear as PrPSc accumulates in the OPL. a In an uninfected mouse, concentrations of PrPC (magenta, yellow arrows) lie vitread to cone pedicles (dark space, yellow arrowhead) outlined by glucose transporter 1 (GLUT1) a membrane-associated protein. Rod spherules (red arrowhead) often have tiny faint patches of PrPC (red arrow) adjacent to their membranes. b At $118 \mathrm{dpi}$, cone pedicles are less frequent and the distribution of PrP is more punctate and widespread, suggesting PrPSc deposits. $\mathrm{c}$ at $153 \mathrm{dpi}$ OPL has thinned significantly, most rod spherules have disappeared, and PrPSc is now in dense punctate patches. ONL has thinned to 1-2 nuclei. Scale bar $=5 \mu \mathrm{m} . \mathrm{a}, \mathrm{b}, \mathrm{c}$ are images of optical slices with total $\mathrm{z}$-depth $=1 \mu \mathrm{m}$

\section{Acknowledgments}

The authors thank Katie Williams for technical assistance with mouse anesthesia, observation and necropsy, Nancy Kurtz, Lori Lubke and Dan Long, for technical histology assistance, Dave Dorward for electron microscopy technical assistance, Tylor Lewis from the Department of Ophthalmology at Duke University Medical Center for technical advice on vibratome sectioning of retinal tissue for electron microscopy processing, and Jeffrey Severson for animal husbandry, and Drs. James Carroll, Byron Caughey, Cathryn Haigh, Suzette Priola, and Clayton Winkler for advice on manuscript preparation.

\section{Author contributions}

JS designed study, gathered and analyzed pathology data from all sources, and wrote manuscript. BR designed study, carried out animal experiments, and edited manuscript. JL gathered and analyzed confocal datasets and edited manuscript. CS prepared samples for electron microscopy, gathered and analyzed electron microscopy data and edited manuscript. BC designed study, analyzed pathology data, and wrote manuscript.

\section{Funding}

Open Access funding provided by the National Institutes of Health $(\mathrm{NIH})$.. This research was supported by the Intramural Research Program (DIR) of the National Institute of Allergy and Infectious Diseases (NIAID) of the United States, National Institutes of Health $(\mathrm{NIH})$.

\section{Availability of data and material}

The data supporting the conclusions of this article are included within the article. Original slides, tissues and photographs are retained. All reagents and animals used in this study are available from scientific supply companies, except the anti-PrP antibody D13, which depending on supply, may be available upon request.

\section{Ethics statement}

All mice were housed at the Rocky Mountain Laboratories (RML) in an AAALAC-accredited facility in compliance with guidelines provided by the Guide for the Care and Use of Laboratory Animals (Institute for Laboratory Animal Research Council). Experimentation followed RML Animal Care and Use Committee approved protocol 2016-042.

\section{Consent for publication}

Not applicable.

\section{Competing interest}

The authors declare that they have no conflict of interest.

\footnotetext{
Author details

${ }^{1}$ Laboratory of Persistent Viral Diseases, Rocky Mountain Laboratories, National Institute of Allergy and Infectious Diseases, National Institutes of Health, 903 South Fourth Street, Hamilton, MT 59840, USA. ${ }^{2}$ Research Technologies Branch, Rocky Mountain Laboratories, National Institute of Allergy and Infectious Diseases, National Institutes of Health, Hamilton, MT 59840, USA.
}

Received: 4 December 2020 Accepted: 9 January 2021

Published online: 29 January 2021

\section{References}

1. Aboelnour A, Van der Spuy J, Powner M, Jeffery G (2017) Primate retinal cones express phosphorylated tau associated with neuronal degeneration yet survive in old age. Exp Eye Res 165:105-108. https://doi. org/10.1016/j.exer.2017.09.013

2. Arshavsky VY (2003) Protein translocation in photoreceptor light adaptation: a common theme in vertebrate and invertebrate vision. Sci STKE 2003:PE43. doi:https://doi.org/10.1126/stke.2003.204.pe43

3. Ashok A, Singh N, Chaudhary S, Bellamkonda V, Kritikos AE, Wise AS, Rana N, McDonald D, Ayyagari R (2020) Retinal degeneration and Alzheimer's disease: an evolving link. Int J Mol Sci. https://doi.org/10.3390/ijms211972 90

4. Brundin P, Melki R, Kopito R (2010) Prion-like transmission of protein aggregates in neurodegenerative diseases. Nat Rev Mol Cell Biol 11:301-307. https://doi.org/10.1038/nrm2873

5. Buyukmihci N, Goehring-Harmon F, Marsh RF (1982) Photoreceptor degeneration preceding clinical scrapie encephalopathy in hamsters. J Comp Neurol 205:49-54. https://doi.org/10.1002/cne.902050105

6. Buyukmihci N, Rorvik M, Marsh RF (1980) Replication of the scrapie agent in ocular neural tissues. Proc Natl Acad Sci USA 77:1169-1171

7. Carroll JA, Race B, Williams K, Striebel J, Chesebro B (2018) Microglia are critical in host defense against prion disease. J Virol. https://doi. org/10.1128/JVI.00549-18

8. Carroll JA, Striebel JF, Rangel A, Woods T, Phillips K, Peterson KE, Race B, Chesebro B (2016) Prion strain differences in accumulation of PrPSC on neurons and glia are associated with similar expression profiles of neuroinflammatory genes: comparison of three prion strains. PLoS Pathog 12:e1005551. https://doi.org/10.1371/journal.ppat.1005551

9. Caughey B, Baron GS, Chesebro B, Jeffrey M (2009) Getting a grip on prions: oligomers, amyloids, and pathological membrane interactions. Annu Rev Biochem 78:177-204. https://doi.org/10.1146/annurev.bioch em.78.082907.145410

10. Chishti MA, Strome R, Carlson GA, Westaway D (1997) Syrian hamster prion protein $(\operatorname{Pr} P(C))$ is expressed in photoreceptor cells of the adult retina. Neurosci Lett 234:11-14. https://doi.org/10.1016/s0304 -3940(97)00669-1

11. Clavaguera F, Duyckaerts C, Haik S (2020) Prion-like properties of Tau assemblies. Curr Opin Neurobiol 61:49-57. https://doi.org/10.1016/j. conb.2019.11.022

12. Cunningham C, Deacon R, Wells H, Boche D, Waters S, Diniz CP, Scott H, Rawlins JN, Perry VH (2003) Synaptic changes characterize early behavioural signs in the ME7 model of murine prion disease. Eur J Neurosci 17:2147-2155. https://doi.org/10.1046/j.1460-9568.2003.02662.x

13. Euler T, Haverkamp S, Schubert T, Baden T (2014) Retinal bipolar cells: elementary building blocks of vision. Nat Rev Neurosci 15:507-519. https ://doi.org/10.1038/nrn3783

14. Fain G, Sampath AP (2018) Rod and cone interactions in the retina. F1000Res 7. doi:https://doi.org/10.12688/f1000research.14412.1

15. Foster JD, Fraser H, Bruce ME (1986) Retinopathy in mice with experimental scrapie. Neuropathol Appl Neurobiol 12:185-196

16. Fraser $\mathrm{H}$ (1982) Neuronal spread of scrapie agent and targeting of lesions within the retino-tectal pathway. Nature 295:149-150. https://doi. org/10.1038/295149a0

17. Frigg $R$, Wenzel A, Samardzija M, Oesch B, Wariwoda $H$, Navarini AA, Seeliger MW, Tanimoto N, Reme C, Grimm C (2006) The prion protein is neuroprotective against retinal degeneration in vivo. Exp Eye Res 83:1350-1358. https://doi.org/10.1016/j.exer.2006.07.010

18. Gomez-Nicola D, Fransen NL, Suzzi S, Perry VH (2013) Regulation of microglial proliferation during chronic neurodegeneration. J Neurosci 33:2481-2493. https://doi.org/10.1523/JNEUROSCI.4440-12.2013

19. Gong J, Jellali A, Forster V, Mutterer J, Dubus E, Altrock WD, Sahel JA, Rendon A, Picaud S (2007) The toxicity of the PrP106-126 prion peptide on cultured photoreceptors correlates with the prion protein distribution in the mammalian and human retina. Am J Pathol 170:1314-1324. https://doi.org/10.2353/ajpath.2007.060340 
20. Greenlee MH, Smith JD, Platt EM, Juarez JR, Timms LL, Greenlee JJ (2015) Changes in retinal function and morphology are early clinical signs of disease in cattle with bovine spongiform encephalopathy. PLoS ONE 10:e0119431. https://doi.org/10.1371/journal.pone.0119431

21. Hamir AN, Miller JM, Cutlip RC, Kunkle RA, Jenny AL, Stack MJ, Chaplin MJ, Richt JA (2004) Transmission of sheep scrapie to elk (Cervus elaphus nelsoni) by intracerebral inoculation: final outcome of the experiment. J Vet Diagn Invest 16:316-321. https://doi.org/10.1177/10406 3870401600410

22. Hasegawa M, Nonaka T, Masuda-Suzukake M (2017) Prion-like mechanisms and potential therapeutic targets in neurodegenerative disorders. Pharmacol Ther 172:22-33. https://doi.org/10.1016/j.pharm thera.2016.11.010

23. Head MW, Northcott V, Rennison K, Ritchie D, McCardle L, Bunn TJ, McLennan NF, Ironside JW, Tullo AB, Bonshek RE (2003) Prion protein accumulation in eyes of patients with sporadic and variant Creutzfeldt-Jakob disease. Invest Ophthalmol Vis Sci 44:342-346

24. Head MW, Peden AH, Yull HM, Ritchie DL, Bonshek RE, Tullo AB, Ironside JW (2005) Abnormal prion protein in the retina of the most commonly occurring subtype of sporadic Creutzfeldt-Jakob disease. Br J Ophthalmol 89:1131-1133. https://doi.org/10.1136/bjo.2004.063495

25. Hughes D, Halliday M (2017) What is our current understanding of PrP(Sc)-associated neurotoxicity and its molecular underpinnings? Pathogens. https://doi.org/10.3390/pathogens6040063

26. Jaunmuktane Z, Brandner S (2020) Invited review: the role of prion-like mechanisms in neurodegenerative diseases. Neuropathol Appl Neurobiol 46:522-545. https://doi.org/10.1111/nan.12592

27. Jeffrey M, Halliday WG, Bell J, Johnston AR, MacLeod NK, Ingham C, Sayers AR, Brown DA, Fraser JR (2000) Synapse loss associated with abnormal PrP precedes neuronal degeneration in the scrapie-infected murine hippocampus. Neuropathol Appl Neurobiol 26:41-54. https:// doi.org/10.1046/j.1365-2990.2000.00216.x

28. Kercher L, Favara C, Chan CC, Race R, Chesebro B (2004) Differences in scrapie-induced pathology of the retina and brain in transgenic mice that express hamster prion protein in neurons, astrocytes, or multiple cell types. Am J Pathol 165:2055-2067. https://doi.org/10.1016/S0002 -9440(10)63256-7

29. Kercher L, Favara C, Striebel JF, LaCasse R, Chesebro B (2007) Prion protein expression differences in microglia and astroglia influence scrapieinduced neurodegeneration in the retina and brain of transgenic mice. J Virol 81:10340-10351. https://doi.org/10.1128/JVI.00865-07

30. Klingeborn M, Race B, Meade-White KD, Rosenke R, Striebel JF, Chesebro B (2011) Crucial role for prion protein membrane anchoring in the neuroinvasion and neural spread of prion infection. J Virol 85:14841494. https://doi.org/10.1128/JVI.02167-10

31. Liu B, Rasool S, Yang Z, Glabe CG, Schreiber SS, Ge J, Tan Z (2009) Amyloidpeptide vaccinations reduce $\{$ beta\}-amyloid plaques but exacerbate vascular deposition and inflammation in the retina of Alzheimer's transgenic mice. Am J Pathol 175:2099-2110. https://doi.org/10.2353/ajpat h.2009.090159

32. Liu C, Zhang CW, Zhou Y, Wong WQ, Lee LC, Ong WY, Yoon SO, Hong W, Fu XY, Soong TW, Koo EH, Stanton LW, Lim KL, Xiao ZC, Dawe GS (2018) APP upregulation contributes to retinal ganglion cell degeneration via JNK3. Cell Death Differ 25:661-676. https://doi.org/10.1038/s4141 8-017-0005-3

33. Matsunaga Y, Peretz D, Williamson A, Burton D, Mehlhorn I, Groth D, Cohen FE, Prusiner SB, Baldwin MA (2001) Cryptic epitopes in N-terminally truncated prion protein are exposed in the full-length molecule: dependence of conformation on $\mathrm{pH}$. Proteins 44:1 10-118

34. Mendes HF, van der Spuy J, Chapple JP, Cheetham ME (2005) Mechanisms of cell death in rhodopsin retinitis pigmentosa: implications for therapy. Trends Mol Med 11:177-185. https://doi.org/10.1016/j.molme d.2005.02.007

35. Mirzaei N, Shi H, Oviatt M, Doustar J, Rentsendorj A, Fuchs DT, Sheyn J, Black KL, Koronyo Y, Koronyo-Hamaoui M (2020) Alzheimer's retinopathy: seeing disease in the eyes. Front Neurosci 14:921. https://doi. org/10.3389/fnins.2020.00921

36. Moser T, Grabner CP, Schmitz F (2020) Sensory processing at ribbon synapses in the retina and the cochlea. Physiol Rev 100:103-144. https:// doi.org/10.1152/physrev.00026.2018
37. Murakami Y, Ikeda Y, Nakatake S, Tachibana T, Fujiwara K, Yoshida N, Notomi S, Nakao S, Hisatomi T, Miller JW, Vavvas DG, Sonoda KH, Ishibashi T (2015) Necrotic enlargement of cone photoreceptor cells and the release of high-mobility group box-1 in retinitis pigmentosa. Cell Death Discov 1:15058. https://doi.org/10.1038/cddiscovery.2015.58

38. Narayan DS, Chidlow G, Wood JP, Casson RJ (2017) Glucose metabolism in mammalian photoreceptor inner and outer segments. Clin Exp Ophthalmol 45:730-741. https://doi.org/10.1111/ceo.12952

39. Narayan DS, Wood JP, Chidlow G, Casson RJ (2016) A review of the mechanisms of cone degeneration in retinitis pigmentosa. Acta Ophthalmol 94:748-754. https://doi.org/10.1111/aos.13141

40. Newton F, Megaw R (2020) Mechanisms of photoreceptor death in retinitis pigmentosa. Genes (Basel). https://doi.org/10.3390/genes11101120

41. Orru CD, Soldau K, Cordano C, Llibre-Guerra J, Green AJ, Sanchez H, Groveman BR, Edland SD, Safar JG, Lin JH, Caughey B, Geschwind MD, Sigurdson CJ (2018) Prion seeds distribute throughout the eyes of sporadic Creutzfeldt-Jakob disease patients. MBio. https://doi.org/10.1128/ mBio.02095-18

42. Puthussery T, Gayet-Primo J, Taylor WR (2010) Localization of the calciumbinding protein secretagogin in cone bipolar cells of the mammalian retina. J Comp Neurol 518:513-525. https://doi.org/10.1002/cne.22234

43. Rachel RA, Li T, Swaroop A (2012) Photoreceptor sensory cilia and ciliopathies: focus on CEP290. RPGR and their interacting proteins Cilia 1:22. https://doi.org/10.1186/2046-2530-1-22

44. Ramirez Al, de Hoz R, Salobrar-Garcia E, Salazar JJ, Rojas B, Ajoy D, LopezCuenca I, Rojas P, Trivino A, Ramirez JM (2017) The role of microglia in retinal neurodegeneration: Alzheimer's disease, parkinson, and glaucoma. Front Aging Neurosci 9:214. https://doi.org/10.3389/fnagi.2017.00214

45. Ratnayaka JA, Serpell LC, Lotery AJ (2015) Dementia of the eye: the role of amyloid beta in retinal degeneration. Eye (Lond) 29:1013-1026. https:// doi.org/10.1038/eye.2015.100

46. Silverman SM, Wong WT (2018) Microglia in the retina: roles in development, maturity, and disease. Annu Rev Vis Sci 4:45-77. https://doi. org/10.1146/annurev-vision-091517-034425

47. Singh N, Chaudhary S, Ashok A, Lindner E (2020) Prions and prion diseases: insights from the eye. Exp Eye Res 199:108200. https://doi. org/10.1016/j.exer.2020.108200

48. Siskova Z, Page A, O'Connor V, Perry VH (2009) Degenerating synaptic boutons in prion disease: microglia activation without synaptic stripping. Am J Pathol 175:1610-1621. https://doi.org/10.2353/ajpath.2009.090372

49. Slepak VZ, Hurley JB (2008) Mechanism of light-induced translocation of arrestin and transducin in photoreceptors: interaction-restricted diffusion. IUBMB Life 60:2-9. https://doi.org/10.1002/iub.7

50. Smith JD, Greenlee JJ, Hamir AN, West Greenlee MH (2008) Retinal cell types are differentially affected in sheep with scrapie. J Comp Pathol 138:12-22. https://doi.org/10.1016/j.jcpa.2007.09.002

51. Soto C, Pritzkow S (2018) Protein misfolding, aggregation, and conformational strains in neurodegenerative diseases. Nat Neurosci 21:1332-1340. https://doi.org/10.1038/s41593-018-0235-9

52. Spraker TR, Zink RR, Cummings BA, Wild MA, Miller MW, O'Rourke KI (2002) Comparison of histological lesions and immunohistochemical staining of proteinase-resistant prion protein in a naturally occurring spongiform encephalopathy of free-ranging mule deer (Odocoileus hemionus) with those of chronic wasting disease of captive mule deer. Vet Pathol 39:110-119. https://doi.org/10.1354/vp.39-1-110

53. Steinert JR (2015) Prion protein as a mediator of synaptic transmission. Commun Integr Biol 8:e1063753. https://doi.org/10.1080/19420 889.2015.1063753

54. Striebel JF, Race B, Williams K, Carroll JA, Klingeborn M, Chesebro B (2019) Microglia are not required for prion-induced retinal photoreceptor degeneration. Acta Neuropathol Commun 7:48. https://doi.org/10.1186/ s40478-019-0702-x

55. Takao M, Kimura H, Kitamoto T, Mihara B (2018) PrP(res) deposition in the retina is a common finding of sporadic, familial and iatrogenic Creutzfeldt-Jakob diseases (CJD). Acta Neuropathol Commun 6:78. https ://doi.org/10.1186/s40478-018-0582-5

56. Thiadens AA, Phan TM, Zekveld-Vroon RC, Leroy BP, van Born LI, Hoyng CB, Klaver CC, Writing Committee for the Cone Disorders study Group C, Roosing S, Pott JW, van Schooneveld MJ, van Moll-Ramirez N, van Genderen MM, Boon CJ, van Hollander Al, Bergen AA, De Baere E, Cremers FP, Lotery AJ (2012) Clinical course, genetic etiology, and visual outcome in 
cone and cone-rod dystrophy. Ophthalmology 119(819):826. https://doi. org/10.1016/j.ophtha.2011.10.011

57. Veys L, Vandenabeele M, Ortuno-Lizaran I, Baekelandt V, Cuenca N, Moons L, De Groef L (2019) Retinal alpha-synuclein deposits in Parkinson's disease patients and animal models. Acta Neuropathol 137:379-395. https:// doi.org/10.1007/s00401-018-01956-z

58. West Greenlee MH, Lind M, Kokemuller R, Mammadova N, Kondru N, Manne S, Smith J, Kanthasamy A, Greenlee J (2016) Temporal resolution of misfolded prion protein transport, accumulation, glial activation, and neuronal death in the retinas of mice inoculated with scrapie. Am J Pathol 186:2302-2309. https://doi.org/10.1016/j.ajpath.2016.05.018

59. Yang J, Gao J, Adamian M, Wen XH, Pawlyk B, Zhang L, Sanderson MJ, Zuo J, Makino CL, Li T (2005) The ciliary rootlet maintains long-term stability of sensory cilia. Mol Cell Biol 25:4129-4137. https://doi.org/10.1128/ MCB.25.10.4129-4137.2005

60. Ye X (2009) Visual pathology in animal prion diseases. Histol Histopathol 24:1563-1577. https://doi.org/10.14670/HH-24.1563

61. Zamponi E, Pigino GF (2019) Protein misfolding, signaling abnormalities and altered fast axonal transport: implications for Alzheimer and prion diseases. Front Cell Neurosci 13:350. https://doi.org/10.3389/fncel 2019.00350

\section{Publisher's Note}

Springer Nature remains neutral with regard to jurisdictional claims in published maps and institutional affiliations.
Ready to submit your research? Choose BMC and benefit from:

- fast, convenient online submission

- thorough peer review by experienced researchers in your field

- rapid publication on acceptance

- support for research data, including large and complex data types

- gold Open Access which fosters wider collaboration and increased citations

- maximum visibility for your research: over $100 \mathrm{M}$ website views per year

At BMC, research is always in progress.

Learn more biomedcentral.com/submissions 